\title{
Impact of expanded FDA indication for icosapent ethyl on enhanced cardiovascular residual risk reduction
}

\author{
William E Boden*,1 (D), Seth Baum², Peter P Toth ${ }^{3}$, Sergio Fazio ${ }^{4}$ \& Deepak L Bhatt ${ }^{5}$ \\ ${ }^{1}$ VA New England Healthcare System, Boston, MA, \& Boston University School of Medicine, Boston, MA 02130, USA \\ ${ }^{2}$ Boca Raton Regional Hospital, Boca Raton, FL 33486, USA \\ ${ }^{3}$ CGH Medical Center, Sterling, IL, Johns Hopkins University School of Medicine, Baltimore, MD 61081, USA \\ ${ }^{4}$ Oregon Health \& Science University, Portland, OR 97239, USA \\ ${ }^{5}$ Brigham \& Women's Hospital Heart \& Vascular Center \& Harvard Medical School, Boston, MA 02115, USA \\ *Author for correspondence: Tel.: +1 857364 4201; William.Boden@va.gov
}

Hypertriglyceridemia is associated with increased cardiovascular disease (CVD) risk. The Reduction of Cardiovascular Events with Icosapent Ethyl-Intervention Trial (REDUCE-IT) demonstrated that the purified, stable ethyl ester of eicosapentaenoic acid, icosapent ethyl (IPE), added to statins reduced CVD events by $25 \%(p<0.001)$, leading to an expanded indication in the USA. IPE is now approved as an adjunct to maximally tolerated statins to reduce CVD event risk in adults with triglyceride (TG) levels $\geq 150 \mathrm{mg} / \mathrm{dl}$ and either established CVD or diabetes mellitus plus $\geq 2$ additional CVD risk factors. The new indication allows co-administration of IPE for elevated TG levels with statin treatment, enabling effective residual risk reduction in a broader at-risk population beyond what can be achieved with intensive low-density lipoprotein cholesterol control alone.

First draft submitted: 29 June 2020; Accepted for publication: 19 August 2020; Published online: 22 September 2020

Keywords: cardiovascular disease • eicosapentaenoic acid • icosapent ethyl • heart diseases • hypertriglyceridemia - triglycerides

Atherosclerotic cardiovascular disease (ASCVD) remains the most common cause of morbidity and mortality in the USA and globally [1-5]. Hypertriglyceridemia is associated with increased ASCVD risk, independent of low-density lipoprotein cholesterol (LDL-C) control [6]. Triglyceride (TG)-lowering therapies such as niacin, fibrates and mixed omega-3 fatty acids have not demonstrated cardiovascular disease (CVD) risk reduction on top of contemporary medical therapy including statins [7].

Icosapent ethyl (IPE), a highly purified, stable ethyl ester of eicosapentaenoic acid (EPA), was originally approved by the US FDA as an adjunct to diet for treatment of adults with severe $(\geq 500 \mathrm{mg} / \mathrm{dl})$ hypertriglyceridemia [8]. Addition of $4 \mathrm{~g} /$ day of IPE to statin-controlled patients with elevated TG levels ( $\geq 150 \mathrm{mg} / \mathrm{dl}$ ) and high risk for ASCVD events resulted in reduction of ASCVD events compared with statin treatment alone in the Reduction of Cardiovascular Events with Icosapent Ethyl-Intervention Trial (REDUCE-IT) [9]. On the basis of the REDUCE-IT findings, the FDA recently approved an expanded CVD risk reduction indication for IPE [8].

This narrative review will discuss the role of TG and TG-lowering treatments in ASCVD risk reduction, summarize the results of the REDUCE-IT trial and highlight the clinical and economic implications of the FDA's recent decision to approve IPE as the first TG-lowering treatment indicated for ASCVD residual risk reduction.

\section{Overview of hypertriglyceridemia: clinical \& economic impact}

Biology, epidemiology \& clinical burden of hypertriglyceridemia

Increases in TG-rich lipoproteins (TRL), such as chylomicrons and very-low-density lipoproteins (VLDL), result in hypertriglyceridemia [10]. Primary lipoprotein phenotypes characterized by hypertriglyceridemia, as defined by Fredrickson, Levy and Lees, are summarized in Table 1 [11]. Common underlying primary causes of hypertriglyceridemia include familial hypertriglyceridemia, which is caused by excess hepatic VLDL production and 
Table 1. Frederickson-Levy phenotypes characterized by hypertriglyceridemia ${ }^{\dagger}$

\begin{tabular}{|c|c|c|}
\hline Frederickson-Levy phenotype & Main features & Diagnostic criteria \\
\hline Type I & Chylomicron excess & TG:TC ratio $>10$ and VLDL-C $<90$ th percentile \\
\hline Type III & Remnant lipoprotein cholesterol excess & VLDL-C:TG ratio $>0.3, \mathrm{TG}>130 \mathrm{mg} / \mathrm{dl}$ and $\mathrm{LDL}-\mathrm{C}<90$ th percentile \\
\hline Type IV & VLDL-C excess & VLDL-C $>90$ th percentile, LDL-C $<90$ th percentile and VLDL-C:TG ratio $<0.3$ \\
\hline Type V & Chylomicron and VLDL-C excess & TG:TC ratio $>10$ and VLDL-C $>90$ th percentile \\
\hline \multicolumn{3}{|c|}{$\begin{array}{l}\dagger \text { Not listed within the table are phenotypes primarily characterized by high LDL-C: type lla (main feature is LDL-C excess; diagnostic criteria are } L D L-C>90 t h \text { percentile, VLDL-C } \\
<90 \text { th percentile and VLDL-C:TG ratio <0.3) and type Ilb (main features are LDL-C and VLDL-C excess; diagnostic criteria are LDL-C, VLDL-C }>90 \text { th percentile and VLDL-C:TG ratio } \\
<0.3 \text { ). } \\
\text { LDL-C: Low-density lipoprotein cholesterol; TG: Triglyceride; VLDL-C: Very-low-density lipoprotein cholesterol. } \\
\text { Reproduced from [11], CC BY-NC-SA. }\end{array}$} \\
\hline
\end{tabular}

\begin{tabular}{|c|c|c|c|}
\hline Genetic target polymorphism & Pathogenesis & Typical lipid/lipoprotein profile & Ref. \\
\hline Apo C2 deficiency & $\begin{array}{l}\text { Absence of needed cofactor, apo C2, leads to increased } \\
\text { chylomicrons }\end{array}$ & $\begin{array}{l}\text { Homozygotes TG:cholesterol ratio } \\
10: 1 ; \text { TG }>1000 \mathrm{mg} / \mathrm{dl} \text {; increased } \\
\text { chylomicrons } \\
\text { Obligate heterozygotes with normal } \\
\text { TG despite apo C2 levels } \sim 30-50 \% \text { of } \\
\text { normal }\end{array}$ & {$[10,12]$} \\
\hline Apo C3 & $\begin{array}{l}\text { Deficiency in apo C3 associated with low TG levels; gain of function } \\
\text { mutation associated with enhanced hepatic de novo lipogenesis }\end{array}$ & & {$[13,14]$} \\
\hline Angiopoietin-like protein 3 and 4 & Loss of function mutations associated with lower TG levels & & {$[13,15]$} \\
\hline Apo A5 deficiency & $\begin{array}{l}\text { Mutations in the APOA5 gene, which lead to truncated apo A5 } \\
\text { devoid of lipid-binding domains located in the carboxy-terminal } \\
\text { end of the protein }\end{array}$ & $\begin{array}{l}\text { Homozygotes: TG:cholesterol ratio } \\
10: 1 ; \text { TG }>1000 \mathrm{mg} / \mathrm{dl} \text {; increased } \\
\text { chylomicrons }\end{array}$ & {$[10,12,16]$} \\
\hline Lipoprotein lipase deficiency & $\begin{array}{l}\text { Very low or undetectable levels of lipoprotein lipase lead to } \\
\text { increased chylomicrons; circulating inhibitor to lipoprotein lipase } \\
\text { has been reported }\end{array}$ & $\begin{array}{l}\text { Homozygotes: TG:cholesterol ratio } 10: 1 ; \\
\text { TG }>1000 \mathrm{mg} / \mathrm{dl} ; \text { increased } \\
\text { chylomicrons }\end{array}$ & {$[10,12]$} \\
\hline Hepatic lipase deficiency & $\begin{array}{l}\text { Relatively rare } L I P C \text { mutations lead to loss in circulating hepatic } \\
\text { lipase activity (due to impaired secretion or inactive enzyme) }\end{array}$ & $\begin{array}{l}\text { Increase in TG-rich HDL and VLDL } \\
\text { remnants }\end{array}$ & [17] \\
\hline $\begin{array}{l}\text { Glycosylphosphatidylinositol- } \\
\text { anchored HDL-binding protein } \\
\text { (GPIHBP1) deficiency }\end{array}$ & $\begin{array}{l}\text { Mutations in GPIHBP1 may reduce binding to LPL and hydrolysis of } \\
\text { chylomicron TGs }\end{array}$ & $\begin{array}{l}\text { TG:cholesterol ratio } 7: 1 ; \mathrm{TG} \\
>500 \mathrm{mg} / \mathrm{dl} \text {; increased chylomicrons } \\
\text { partially responsive to low-fat diet }\end{array}$ & {$[10,12]$} \\
\hline
\end{tabular}

is characterized by normal cholesterol levels, and familial combined hyperlipidemia, which is caused by poorly defined polygenic influences on lipoprotein metabolism [12]. Genetic polymorphisms that may impact TG levels are summarized in Table 2 [10,12-17]. Secondary causes of hypertriglyceridemia include diabetes mellitus, central obesity, dietary excess, hypothyroidism and chronic kidney disease [12]. One quarter of US adults, and up to a third of those on statins, have elevated TG levels ( $\geq 150 \mathrm{mg} / \mathrm{dl}$ ), likely due to contributions of obesity and other metabolic diseases [10,18-21].

Hypertriglyceridemia is associated with increased ASCVD risk, independent of LDL-C control [6,21-27]. For example, a recent claims-based analysis of over 20,000 statin-treated patients with diabetes and/or ASCVD found that, despite having generally controlled LDL-C, patients in the high-TG cohort (TG levels $200-499 \mathrm{mg} / \mathrm{dl}$ ) had a $34.9 \%$ higher risk of major CVD events than a propensity-matched cohort with TG levels $<150 \mathrm{mg} / \mathrm{dl}$ and high-density lipoprotein cholesterol (HDL-C) levels $>40 \mathrm{mg} / \mathrm{dl}$ [6]. A meta-analysis of 61 prospective clinical trials that assessed the association between baseline blood TG levels with CVD mortality (33 studies) or with all-cause mortality (38 studies) reported that, compared with TG levels $90-149 \mathrm{mg} / \mathrm{dl}$, TG levels $150-199 \mathrm{mg} / \mathrm{dl}$ were associated with a 15 and $9 \%$ increased risk of CVD mortality and all-cause mortality, respectively; TG levels $\geq 200 \mathrm{mg} / \mathrm{dl}$ were associated with even greater increases in risk of 25 and $20 \%$, respectively [28]. Consistent with these clinical findings, genetic data, including Mendelian randomization studies, support an association between elevated TG levels and ASCVD risk [29-31]. 


\section{Economic burden}

The economic consequences of residual CVD risk associated with hypertriglyceridemia are substantial [6,22,25,26]. An analysis based on National Health and Nutrition Examination Survey (NHANES) 2007-2014 surveys and insurance claims data for a sample of US adults aged $\geq 45$ years found that TG levels $\geq 150 \mathrm{mg} / \mathrm{dl}$ translated to a projected overall additional cost burden of US $\$ 10.7$ billion annually compared with TG levels $<150 \mathrm{mg} / \mathrm{dl}$ ( $95 \%$ CI, $\$ 6.8-14.6$ billion) [22].

\section{Current role of TG-lowering drugs in reducing ASCVD event risk}

\section{Overview of niacin studies}

Clinical trials assessing the use of niacin in addition to statin treatment for CVD prevention are summarized in Table 3 [32-38]. Neither the Atherothrombosis Intervention in Metabolic Syndrome with Low HDL/High Triglycerides: Impact on Global Health Outcomes (AIM-HIGH) nor the Heart Protection Study 2-Treatment of HDL to Reduce the Incidence of Vascular Events (HPS2-THRIVE) achieved its primary cardiovascular end point [32,33]. Findings in subgroup analyses of patients with higher TG levels were inconsistent. While a trend toward CVD event risk reduction for niacin versus placebo was found in a post hoc analysis of the high-TG/low-HDL-C subgroup of AIM-HIGH [34], no difference between treatment groups was found among high-TG/low-HDL-C patients in HPS2-THRIVE [33].

\section{Overview of fibrate studies}

Details of clinical trials evaluating fibrates for prevention of CVD events are summarized in Table 3. An early study of fibrate monotherapy in the pre-statin era, the Veterans Affairs Cooperative Studies Program High-Density Lipoprotein Cholesterol Intervention Trial (VA-HIT), found that in men with a documented history of coronary heart disease and low HDL-C levels $(\leq 40 \mathrm{mg} / \mathrm{dl})$, gemfibrozil reduced the rate of the primary end point (death from coronary heart disease or nonfatal myocardial infarction [MI]) versus placebo by $22 \%$ (95\% CI: 7-35\%; p $=0.006)$ [35]. However, the subsequent literature has suggested that gemfibrozil should not be combined with statins since inhibition of statin glucuronidation may increase serum statin levels, leading to increased myopathy risk [39]. More recent pharmacokinetic data suggest there are differences in the severity of interactions between gemfibrozil and different statins. Interactions between simvastatin, lovastatin and pravastatin are considered moderate, while interactions between gemfibrozil and rosuvastatin, atorvastatin and pitavastatin are considered minor [40]. These findings have prompted the American Heart Association (AHA) to recommend that combination therapy with gemfibrozil and rosuvastatin, atorvastatin, or pitavastatin may be considered if clinically indicated; nevertheless, statin-fibrate combination therapy with fenofibrate is preferred in those guidelines [40]. However, the American Diabetes Association guidelines note that statins should generally not be combined with either fibrates or niacin as a Level A recommendation [41]. Thus, the CVD risk reduction findings with gemfibrozil are not as relevant in the contemporary statin era. Fenofibrate has been shown to improve activation of ezetimibe by increasing its glucuronidation [42]. However, large, randomized, controlled studies of other fibrates (bezafibrate and fenofibrate) have failed to achieve their primary cardiovascular end points regardless of whether these fibrates were used as monotherapy [36,37] or in combination with statins [38]. Subgroup analyses from these studies have suggested fibrates may lower CVD event risk in patients with higher TG levels, a notion that still needs to be proven prospectively [36-38].

Thus, although niacin and fibrates have TG-lowering effects, large outcomes trials evaluating these treatments as add-on therapy to statins have failed to demonstrate significant ASCVD event risk reduction [32,33,38]. An ongoing clinical trial utilizing a newer fibrate, the Pemafibrate to Reduce Cardiovascular Outcomes by Reducing Triglycerides in Patients With Diabetes (PROMINENT; NCT03071692), is targeting patients with high TG levels (fasting, $200-<500 \mathrm{mg} / \mathrm{dl}$ ) and Type 2 diabetes taking moderate- to high-intensity statin therapy or meeting specified LDL-C criteria ( $\leq 70 \mathrm{mg} / \mathrm{dl}$ within 12 months prior to enrollment or $\leq 100 \mathrm{mg} / \mathrm{dl}$ if statin-intolerant) [43]. Results of this study will help clarify the role of a newer fibrate in addressing residual ASCVD event risk.

\section{Role of omega-3 fatty acids in reducing ASCVD event risk}

Omega-3 fatty acids have been demonstrated to be efficacious in TG lowering [44,45], and may exert pleiotropic effects beyond TG lowering, which could contribute to reduction of residual ASCVD event risk [46,47]. EPA and docosahexaenoic acid (DHA) have distinct biologic functions and electrophysiologic properties [48-50]. While both are incorporated in membrane phospholipids in the $s n-2$ position, EPA appears to have more potent antioxidant 




effects [50,51], preserves membrane structure and maintains normal distribution of membrane cholesterol, inhibits formation of cholesterol crystals, and positively influences the signal transduction pathways related to inflammation and vasodilation [51]. DHA may be neuroprotective [52,53], has lipid-disordering effects that reduce antioxidant activity, may increase membrane fluidity and promote changes in lipid domains [51], and has possible anti-arrhythmic effects due to ion channel modulation [54]. Differential effects of omega-3 fatty acids on LDL-C have also been observed: EPA appears to have a minimal or neutral effect, while DHA has been associated with increased LDL-C levels, though the clinical consequences of this remain uncertain, particularly in subjects taking statins $[44,45]$. 
Table 4. Cardiovascular outcomes trials of mixed omega-3 fatty acids

\begin{tabular}{|c|c|c|c|}
\hline Trial & Treatment and patient population $^{\dagger}$ & Primary finding & Ref. \\
\hline GISSI Prevenzione & $\begin{array}{l}\mathrm{DHA}+\mathrm{EPA}(<1 \mathrm{~g} / \text { day }) \text { vs vitamin E vs } \mathrm{DHA}+\mathrm{EPA} \text { with } \\
\text { vitamin E vs placebo in 11,324 patients within } 3 \text { months } \\
\text { post-MI }\end{array}$ & $\begin{array}{l}\text { DHA + EPA significantly reduced the co-primary composite end } \\
\text { points vs placebo over } 3.5 \text { years: all-cause death, nonfatal MI and } \\
\text { nonfatal stroke was reduced by } 15 \%(95 \% \mathrm{Cl}: 2-26 \% ; \mathrm{p}=0.023) \\
\text { and CV death, nonfatal } \mathrm{MI} \text { and nonfatal stroke was reduced by } \\
20 \%(95 \% \mathrm{Cl}: 5-32 \% ; \mathrm{p}=0.008)\end{array}$ & [55] \\
\hline GISSI Heart Failure & $\begin{array}{l}\text { DHA + EPA ( } 1 \mathrm{~g} / \text { day) vs placebo in } 7046 \text { patients with } \\
\text { clinical evidence of heart failure (those with LVEF }>40 \% \text { had } \\
\text { to have had at least one hospital admission for heart failure } \\
\text { in the prior year); unless contraindicated, patients were also } \\
\text { randomly assigned rosuvastatin } 10 \mathrm{mg} \text { or placebo }\end{array}$ & $\begin{array}{l}\text { DHA + EPA produced a moderate reduction vs placebo in the } \\
\text { coprimary end points over } 3.9 \text { years: reduction in all-cause } \\
\text { mortality risk was } 1.8 \%(95 \% \mathrm{Cl}: 0.3-3.9 \%) \text { and reduction in } \\
\text { mortality or hospitalization for cardiovascular causes risk was } 2.3 \% \\
(95 \% \mathrm{Cl}: 0-4.6 \%)\end{array}$ & [62] \\
\hline OMEGA & $\begin{array}{l}\mathrm{DHA}+\mathrm{EPA}(\sim 1 \mathrm{~g} / \text { day }) \text { vs placebo in } 3851 \text { patients aged } \\
\geq 18 \text { years and admitted to the hospital for acute } \mathrm{Ml}\end{array}$ & $\begin{array}{l}\text { DHA + EPA did not achieve the primary end point of sudden } \\
\text { cardiac death (unexpected death from heart disease within } 1 \mathrm{~h} \text { for } \\
\text { first symptoms or unwitnessed overnight and/or sudden cardiac } \\
\text { arrest within } 1 \mathrm{~h} \text { of first symptoms with initially successful } \\
\text { cardiopulmonary resuscitation and subsequent death during the } \\
\text { hospital stay within } 3 \text { weeks) }\end{array}$ & [56] \\
\hline Alpha Omega & $\begin{array}{l}\text { DHA + EPA ( } 376 \mathrm{mg} / \text { day in a margarine) vs placebo in } 4837 \\
\text { adults aged } 60-80 \text { years who had MI up to } 10 \text { years before } \\
\text { randomization }\end{array}$ & $\begin{array}{l}\text { DHA + EPA did not achieve the primary end point (major } \\
\text { cardiovascular events: fatal and nonfatal cardiovascular events and } \\
\text { the cardiac interventions percutaneous coronary intervention and } \\
\text { coronary artery bypass grafting) }\end{array}$ & [58] \\
\hline ORIGIN & $\begin{array}{l}\mathrm{DHA}+\mathrm{EPA}(<1 \mathrm{~g} / \text { day }) \text { vs placebo in } 12,536 \text { adults aged } \\
\geq 50 \text { years with diabetes/dysglycemia and additional CVD } \\
\text { risk factors }\end{array}$ & $\begin{array}{l}\text { DHA + EPA did not achieve the primary end point of death from } \\
\text { cardiovascular causes }\end{array}$ & [57] \\
\hline $\begin{array}{l}\text { Risk and Prevention } \\
\text { Study }\end{array}$ & $\begin{array}{l}\text { DHA + EPA ( } 1 \mathrm{~g} / \text { day) vs placebo in } 12,513 \text { adults at high risk } \\
\text { for CVD (multiple risk factors), clinical evidence for ASCVD, } \\
\text { but no prior MI }\end{array}$ & $\begin{array}{l}\text { DHA + EPA did not achieve the primary composite end point (time } \\
\text { to death from cardiovascular causes or hospital admission for } \\
\text { cardiovascular causes) }\end{array}$ & [59] \\
\hline ASCEND & $\begin{array}{l}\text { DHA }+ \text { EPA ( }<1 \mathrm{~g} / \text { day) in } 15,480 \text { adults aged } \geq 40 \text { years with } \\
\text { diabetes but no evidence of CVD }\end{array}$ & $\begin{array}{l}\text { DHA + EPA did not achieve the primary composite end point } \\
\text { (nonfatal MI or stroke [excluding confirmed intracranial } \\
\text { hemorrhage], transient ischemic attack, or vascular death } \\
\text { excluding intracranial hemorrhage) }\end{array}$ & [60] \\
\hline VITAL & $\begin{array}{l}\text { DHA }+ \text { EPA }(<1 \mathrm{~g} / \text { day }) \text { and vitamin D vs placebo in } 25,871 \\
\text { men aged } \geq 50 \text { years and women aged } \geq 55 \text { years }\end{array}$ & $\begin{array}{l}\text { DHA + EPA did not achieve the primary end point (major } \\
\text { cardiovascular events [composite of MI, stroke and death from } \\
\text { cardiovascular causes] and invasive cancer of any type) }\end{array}$ & [61] \\
\hline \multicolumn{4}{|c|}{$\begin{array}{l}\text { †Baseline statin use varied widely among these studies: }<5 \% \text { in GISSI-Prevenzione, } 35 \% \text { in VITAL, } 41 \% \text { in risk and prevention, } 54 \% \text { in ORIGIN, } 75 \% \text { in ASCEND, } 86 \% \text { in Alpha } \\
\text { Omega and } 94 \% \text { (at discharge) in OMEGA. } \\
\text { ASCEND: A Study of Cardiovascular Events in Diabetes; DHA: Docosahexaenoic acid; EPA: Eicosapentaenoic acid; GISSI: Gruppo Italiano per lo Studio della Sopravvivenza } \\
\text { nell'Infarto miocardico; HR: Hazard ratio; LVEF: Left ventricular ejection fraction; MI: Myocardial infarction; ORIGIN: Outcome Reduction with an Initial Glargine Intervention; } \\
\text { VITAL, Vitamin D and Omega-3 Trial. }\end{array}$} \\
\hline
\end{tabular}

Overview of mixed omega-3 fatty acid cardiovascular outcomes studies

Clinical trials assessing the impact of mixed omega-3 fatty acids (EPA + DHA) on cardiovascular outcomes have not consistently demonstrated CVD event risk reduction (Table 4) [55-62]. An early open-label clinical trial, Gruppo Italiano per lo Studio della Sopravvivenza nell'Infarto miocardico (GISSI-Prevenzione), found that mixed omega-3 fatty acids (EPA + DHA; <1 g/day) significantly reduced risk of death, nonfatal MI and nonfatal stroke by $15 \%$ (95\% CI: 2-26\%; $\mathrm{p}=0.023$ ) and cardiovascular death, nonfatal MI and nonfatal stroke by $20 \%$ (95\% CI: 5-32\%; p $=0.008$ ) over 3.5 years in patients who had recently had an MI [55]. However, results of GISSI-Prevenzione may not be generalizable to contemporary patient populations; baseline rates of revascularization and use of statin treatment were both $<6 \%$ [55], far below the current standard of care for a population with established ASCVD [63,64]. With the exception of the GISSI-Heart Failure study, which reported modest risk reduction in a population with low statin use [62], subsequent large, high-profile studies of mixed omega-3 fatty acids failed to demonstrate CVD event risk reduction, whether in patients with established ASCVD [56,58] or at risk for ASCVD [57,59].

In recent years, two large-scale outcomes studies of low-dose (1 g fish oil/day as DHA $380 \mathrm{mg}+$ EPA $460 \mathrm{mg}$ ) prescription mixed omega-3 fatty acids failed to achieve their primary cardiovascular end points [60,61]. In A Study of Cardiovascular Events in Diabetes (ASCEND), there was no difference in the occurrence of vascular events between daily mixed omega- 3 fatty acids and placebo over $>7$ years of follow-up in patients with diabetes and no known baseline CVD [60]. Likewise, in the Vitamin D and Omega-3 Trial (VITAL), neither daily mixed omega-3 fatty acids nor vitamin $\mathrm{D}_{3}$ resulted in a significantly lower incidence of major cardiovascular events compared with placebo over more than 5 years of follow-up in a primary prevention population [61]. 
Factors leading to inconsistent findings in mixed omega-3 fatty acid studies may include heterogeneity of mixed omega-3 products, relatively low doses used $(\sim 1 \mathrm{~g} /$ daily), as well as differences in study populations, baseline TG levels and baseline statin use [65,66].

In January 2020, another highly anticipated mixed omega-3 fatty acid trial, the Outcomes Study to Assess Statin Residual Risk Reduction With Epanova in High Cardiovascular Risk Patients With Hypertriglyceridemia (STRENGTH), which investigated a prescription-strength dose ( $4 \mathrm{~g} /$ day) of a free fatty acid EPA + DHA mixture, was discontinued early $[67,68]$. An independent Data Monitoring Committee recommended stopping the trial based on preliminary data that showed the EPA + DHA mixture had a 'low likelihood' of benefiting patients with mixed dyslipidemia and an increased risk of CVD [69].

\section{Early CV outcomes study of EPA alone}

An open-label clinical trial of EPA alone, the Japan EPA Lipid Intervention Study (JELIS), found a 19\% reduction in ASCVD events among 18,645 Japanese patients treated with moderate-dose EPA (1.8 g daily) added to low-dose statin therapy compared with placebo (statin only) (hazard ratio [HR], 0.81; 95\% CI: 0.69-0.95; p = 0.011) [70]. However, the results from JELIS should be taken with some caution. Unlike REDUCE-IT, which will be discussed in the next section, JELIS did not specifically enroll patients with elevated TG levels. Statin intensity was low in JELIS, with the vast majority of patients $(90 \%)$ on simvastatin $5 \mathrm{mg}$ or pravastatin $10 \mathrm{mg}$ [70]. These doses were appropriate for the population studied but may not be generalizable to other populations. The mean attained LDL-C level in JELIS was approximately $136 \mathrm{mg} / \mathrm{dl}$ [70], in contrast to a median attained LDL-C level of $77 \mathrm{mg} / \mathrm{dl}$ in REDUCE-IT [9].

\section{REDUCE-IT}

\section{Cardiovascular risk reduction with IPE}

REDUCE-IT was the first prospective, placebo-controlled, randomized cardiovascular outcomes trial of IPE $4 \mathrm{~g} /$ day ( $2 \mathrm{~g}$ twice daily) in statin-controlled patients with elevated TG levels and established ASCVD or high risk for ASCVD (i.e., diabetes and at least one additional CV risk factor) [9]. The primary efficacy end point (a composite of cardiovascular death, nonfatal MI, nonfatal stroke, coronary revascularization, or unstable angina) occurred in $17.2 \%$ of patients in the IPE versus $22 \%$ of patients in the placebo group (HR: 0.75 ; $95 \%$ CI: 0.68-0.83; $\mathrm{p}<0.001)$ [9]. Thus, compared with placebo, IPE significantly reduced important ASCVD events by $25 \%$ (Figure 1A). The key secondary end point (a composite of cardiovascular death, nonfatal MI, or nonfatal stroke) occurred in $11.2 \%$ of patients in the IPE group versus $14.8 \%$ of patients in the placebo group (HR: 0.74; 95\% CI: $0.65-0.83 ; \mathrm{p}<0.001)$. The numbers needed to treat $(\mathrm{NNT})$ to prevent one primary end point or one key secondary end point event were 21 and 28, respectively, over a median 4.9-year follow-up. In addition, the relative risk of the total (first and subsequent) primary composite end point was significantly reduced by $30 \%$ in the IPE versus placebo group (61 vs 89 events per 1000 patient-years; rate ratio: 0.70; 95\% CI: 0.62-0.78; $\mathrm{p}$ $<0.001$; Figure 1B) [71]. The IPE group had significantly lower relative risks of individual cardiovascular end points compared with placebo, including a $20 \%$ reduction in death due to cardiovascular causes (HR: 0.80 ; $95 \%$ CI: $0.66-0.98$ ), 31\% reduction in MI (HR: 0.69; 95\% CI: 0.58-0.81), $28 \%$ reduction in stroke (HR: 0.72 ; $95 \%$ CI: $0.55-0.93$ ) and $31 \%$ reduction in sudden cardiac death (HR: 0.69; 95\% CI: 0.50-0.96) [9]. In the US subgroup $(\mathrm{n}=3146)$, the primary composite end point rate was $18.2 \%$ in the IPE group versus $24.7 \%$ in the placebo group (HR: 0.69 ; 95\% CI: $0.59-0.80$ ), corresponding to a NNT of 15 . The rate of the key secondary end point was $12.1 \%$ in the IPE group versus $16.6 \%$ in the placebo group (HR: 0.69 ; $95 \%$ CI: $0.57-0.83$ ), corresponding to a NNT of 22 [72].

\section{TG levels in REDUCE-IT}

IPE treatment achieved the primary or key secondary efficacy end points in REDUCE-IT independent of baseline TG levels; additionally, CVD event risk reduction with IPE was not affected by whether TG levels attained at 1 year after randomization were $\geq 150$ or $<150 \mathrm{mg} / \mathrm{dl}$ [9]. Although study inclusion required screening TG levels $\geq 135$ to $<500 \mathrm{mg} / \mathrm{dl}$, baseline TG levels (defined as the average of screening and randomization visit TG levels) ranged from 81 to $1401 \mathrm{mg} / \mathrm{dl}$ [73]. An analysis by TG tertiles across this wide range of baseline TG levels found that IPE significantly reduced the risk of first and total occurrence of the primary composite end point versus placebo in all TG tertiles (TG $\geq 81-\leq 190,>190-\leq 250$ and $>250-\leq 1401 \mathrm{mg} / \mathrm{dl}$ ), with no heterogeneity in the relative risk reduction between these groups [73]. For first occurrence of the primary composite end point, the HRs (95\% CI; 
(A)

Primary composite endpoint

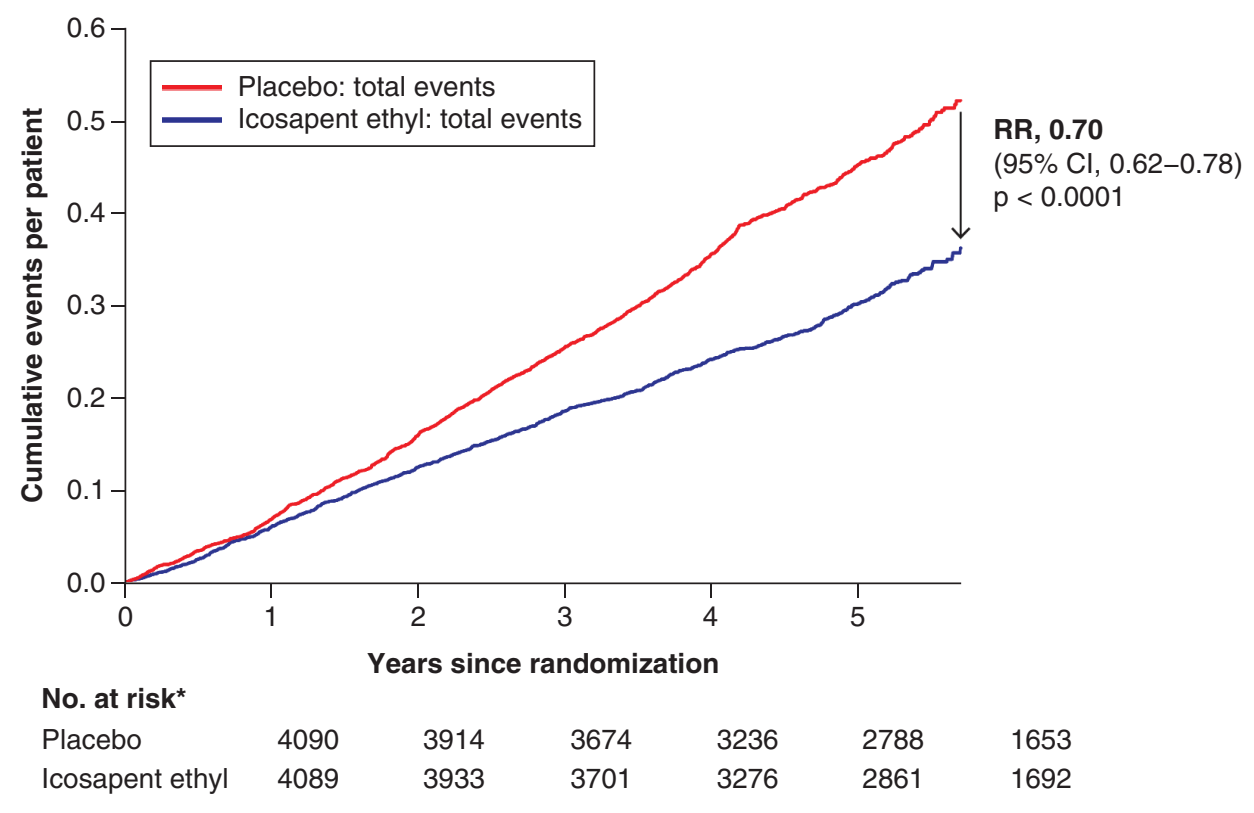

(B)

Key secondary composite endpoint

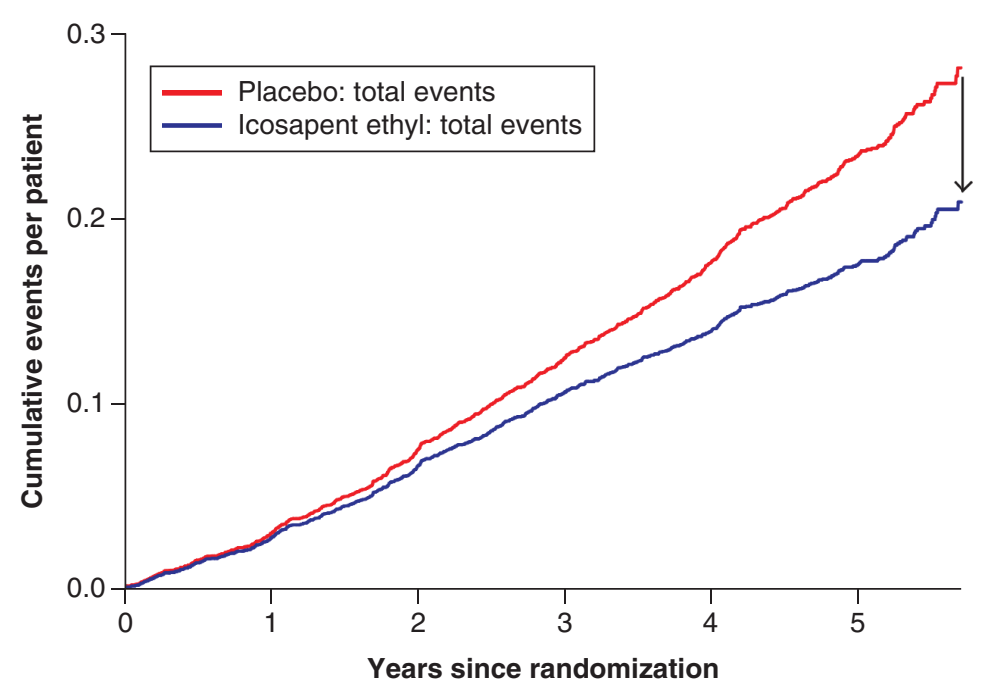

$\mathrm{RR}, 0.72$

$(95 \% \mathrm{Cl}, 0.63-0.82)$ $\mathrm{p}<0.0001$

No. at risk*

$\begin{array}{lllllll}\text { Placebo } & 4090 & 3914 & 3674 & 3236 & 2788 & 1653 \\ \text { Icosapent ethyl } & 4089 & 3933 & 3701 & 3276 & 2861 & 1692\end{array}$

Figure 1. REDUCE-IT primary end point. (A) Time to first primary composite end point event [9]. (B) Total (first and subsequent) primary composite end point events [71].

*The number of patients at risk for recurrent events.

Reproduced with permission from Bhatt et al. [9,71]. CC BY-NC-ND 4.0.

$\mathrm{p}$-value) for the lowest to highest TG tertiles were $0.79(0.66-0.94 ; \mathrm{p}=0.007), 0.80(0.68-0.95 ; \mathrm{p}=0.012)$ and $0.68(0.57-0.80 ; \mathrm{p}<0.001)$, respectively. 


\begin{tabular}{|c|c|c|}
\hline & $\begin{array}{c}\text { EPA } \\
\text { associated with } \\
\text { increases in: }\end{array}$ & $\begin{array}{c}\text { EPA } \\
\text { associated with } \\
\text { decreases in: }\end{array}$ \\
\hline \multicolumn{3}{|l|}{ Condition: } \\
\hline $\begin{array}{l}\text { Endothelial } \\
\text { dysfunction } \\
\text { and oxidative } \\
\text { stress }\end{array}$ & $\begin{array}{l}\text { - Endothelial function } \\
\text { - NO bioavailability }\end{array}$ & $\begin{array}{l}\text { - Cholesterol crystalline } \\
\text { domains } \\
\text { - oxLDL } \\
\text { - RLP-C } \\
\text { - Adhesion of monocytes } \\
\text { - Macrophages } \\
\text { - Foam cells }\end{array}$ \\
\hline $\begin{array}{l}\text { Inflammation } \\
\text { and plaque } \\
\text { growth }\end{array}$ & $\begin{array}{l}\text { - EPA/AA ratio } \\
\text { - IL-10 } \\
\text { - Pro-resolving } \\
\text { mediators }\end{array}$ & $\begin{array}{l}- \text { IL-6 } \\
\cdot \text { ICAM-1 } \\
\text { - hsCRP } \\
\cdot \text { Lp-PLA }\end{array}$ \\
\hline $\begin{array}{l}\text { Unstable } \\
\text { plaque }\end{array}$ & $\begin{array}{l}\text { - Fibrous cap thickness } \\
\text { - Lumen diameter } \\
\text { - Plaque stability }\end{array}$ & $\begin{array}{l}\text { - Plaque volume } \\
\text { - Arterial stiffness } \\
\text { - Plaque vulnerability } \\
\text { - Thrombosis } \\
\text { - Platelet activation }\end{array}$ \\
\hline
\end{tabular}

Figure 2. Pleiotropic effects of EPA.

AA: Arachidonic acid; EPA: Eicosapentaenoic acid; hsCRP: High-sensitivity C-reactive protein; ICAM-1: Intercellular adhesion molecule 1; IL: Interleukin; Lp-PLA2: Lipoprotein-associated phospholipase 2; MMPs: Matrix metalloproteinases; NO: Nitric oxide; oxLDL: Oxidized low-density lipoprotein; RLP-C: Remnant lipoprotein cholesterol.

Data taken from $[47,50]$.

\section{Pleiotropic effects of EPA}

These data support the likelihood that IPE reduced risk of CVD events by mechanisms of EPA beyond TG reduction. Although these mechanisms are not completely understood, they are likely multifactorial, including an association with EPA levels post dosing with $4 \mathrm{~g} /$ day of IPE [9]. A recent evaluation of EPA levels and cardiovascular outcomes in REDUCE-IT found that median serum EPA level in IPE-treated patients increased from $26.1 \mu \mathrm{g} / \mathrm{l}$ at baseline to $158 \mu \mathrm{g} / \mathrm{l}$ at 5 years [74]. The difference in median percent change from baseline between the IPE and placebo groups was $448.1 \%(\mathrm{p}<0.001)$. Achieved EPA levels in the IPE group correlated strongly $(\mathrm{p}<0.001)$ with the primary end point, the key secondary end point, cardiovascular death, MI, stroke, coronary revascularization, unstable angina, sudden cardiac death, cardiac arrest, new heart failure and all-cause mortality [74]. In contrast, changes in biomarker levels such as TGs, LDL-C and high-sensitivity C-reactive protein (hsCRP) had a limited impact on reducing the relative risk of both the primary and secondary end points [74].

The pleiotropic effects of EPA have been reviewed extensively [46,47,50,51] and may include a reduction in lipids, lipoproteins and inflammatory markers; preservation of cell membrane structure and normal distribution of membrane cholesterol [47,51]; increased EPA content in the vessel wall [46,75]; increased circulating EPA/arachidonic acid (AA) ratio (which may be indicative of cardiovascular benefit because high EPA:AA ratios are associated with decreased proinflammatory and pro-aggregatory mediators, whereas low EPA:AA ratios are associated with cardiovascular events including venous thromboembolisms, major adverse limb effects and increased mortality in patients hospitalized for decompensated heart failure) [47,51,76,77]; and inhibited platelet aggregation [47,50] (Figure 2). An analysis of two prior IPE Phase III clinical studies (Multi-center, Placebo-controlled, Randomized, Double-blind, 12-week Study with an Open-label Extension [MARINE] and ANCHOR), found that, compared with placebo, IPE $4 \mathrm{~g} /$ day significantly reduced lipoprotein-associated phospholipase $\mathrm{A}_{2}$ (Lp-PLA $)$ by 14 to $19 \%$ and hsCRP by 22 to 36\% (both p < 0.001) [78]. In addition, EPA is a precursor to specialized pro-resolving mediators (RvE1; RvE2), both of which potently resolve inflammation [79,80]. Of interest, prespecified 9-month interim results from the ongoing Effect of Vascepa on Improving Coronary Atherosclerosis in People with High 
Triglycerides Taking Statin Therapy (EVAPORATE) trial reported that, while there was no significant change in the primary end point of low-attenuation plaque between IPE and placebo, after adjustment for baseline factors, there was slowing of total non-calcified plaque, total plaque (noncalcified + calcified plaque), fibrous plaque and calcified plaque for IPE versus placebo (all $\mathrm{p} \leq 0.011$ ) [81]. The final results of EVAPORATE are eagerly awaited.

\section{Safety \& additional considerations from REDUCE-IT}

IPE was found to be well tolerated in REDUCE-IT, with no significant differences from placebo in the overall rate of adverse events (AEs) or serious AEs (SAEs) leading to discontinuation. Specific AEs that were significantly more common in the IPE group than in the placebo group are important to consider. The rate of serious adverse bleeding events (e.g., gastrointestinal, CNS and other bleeding events) trended toward significance in the IPE versus placebo group $(2.7$ vs $2.1 \% ; \mathrm{p}=0.06)$. However, there were no fatal bleeding events attributable to the study drug in the trial, and no difference between groups in rates of adjudicated hemorrhagic stroke $(0.3$ vs $0.2 \% ; p=0.55)$, serious CNS bleeding ( 0.3 vs $0.2 \%$; $=0.42$ ), or gastrointestinal bleeding ( 1.5 vs $1.1 \% ; p=0.15)$. Of note, the rate of anemia was significantly lower for the IPE group compared with the placebo group ( 4.7 vs $5.8 \% ; p=0.03$ ) [9]. The rate of peripheral edema was higher in the IPE group compared with the placebo group (6.5 vs 5.0\%; $\mathrm{p}$ $=0.002)$; however, there was no significant difference in the prespecified adjudicated tertiary end point of heart failure between groups [9].

Of note, the rate of atrial fibrillation (AF) was higher in the IPE group compared with the placebo group (5.3 vs $3.9 \% ; \mathrm{p}=0.003$ ). Likewise, the rate of hospitalization for $\mathrm{AF}$ or atrial flutter, a prespecified adjudicated tertiary end point, was higher for patients taking IPE compared with placebo (3.1 vs $2.1 \% ; \mathrm{p}=0.004$ ) [9]. However, most of the $\mathrm{AF}$ and/or atrial flutter events observed with IPE in REDUCE-IT occurred in patients with a history of AF and/or atrial flutter at baseline and were not considered serious [8]. Sequelae from AF/flutter such as stroke, MI, cardiac arrest and sudden cardiac death occurred at significantly lower rates in the IPE group compared with placebo in the overall trial. In addition, these arrhythmogenic events occurred at relatively low rates when considered in the context of the observed benefits of treatment with IPE. The FDA examined AF risk-related data and determined that, "given the strength and consistency of the finding of reduction of major adverse cardiovascular events in REDUCE-IT, the benefit-risk assessment favors the use of Vascepa [IPE] for CVD risk reduction in the intended population with caution regarding a potential increase in risk of $A F^{\prime \prime}$ [82].

LDL-C and hsCRP increased from baseline in the placebo group by $\sim 10$ and $\sim 30 \%$, respectively, leading the FDA and others to examine the possibility that the mineral oil placebo used in REDUCE-IT may have impacted these parameters [82]. Exploratory analyses conducted by the FDA suggested that the observed difference in LDL-C and hsCRP levels between the IPE and placebo groups could not account for the robust reduction in CVD event risk [82]. Thus, it was considered unlikely that the mineral oil placebo clinically influenced overall study outcomes in REDUCE-IT. Of interest, an analysis of coronary computed tomography angiography data from two different randomized clinical trials (one using a mineral oil placebo, the other using a nonmineral oil placebo) concluded that progression of plaque volumes was not related to consumption of mineral oil in the quantities used in these placebo capsules [83]. In addition, a meta-analysis examined 21 randomized controlled trials which utilized an oral mineral oil placebo, finding that increases in lipid parameters (LDL-C, HDL-C, TG and total cholesterol) with mineral oil placebo were not significant [84]. However, significant LDL-C increases were observed in patient subgroups with high-baseline statin use and in those with consumption of $>4 \mathrm{~g} /$ day of mineral oil [84].

\section{IPE's FDA indications}

The initial and continuing indication for IPE is as an adjunct to diet to reduce TG levels in adult patients with severe (TG levels $\geq 500 \mathrm{mg} / \mathrm{dl}$ ) hypertriglyceridemia [8]. Following an FDA advisory panel's unanimous vote [85], in December 2019, the FDA approved IPE for an additional indication based on the CVD event risk reduction demonstrated in REDUCE-IT [86]. IPE is the first FDA-approved drug to reduce CVD event risk among patients with elevated TG levels as an add-on to maximally tolerated statin therapy. As such it is important that we examine and clarify/define key aspects of the new indication to ensure access to IPE in patients who would be appropriate candidates for this treatment. 
Table 5. Weighted prevalence of TG $\geq 150 \mathrm{mg} / \mathrm{dl}$ among different subgroups of adults aged 20 and over in NHANES 2007-2014.

\begin{tabular}{|ll|}
\hline Population & Prevalence of TG $\geq 150 \mathrm{mg} / \mathrm{dl}, \%$ (Number/Total Population) \\
\hline Overall & $25.9(56.9 \mathrm{M} / 219.9 \mathrm{M})$ \\
\hline Statin-treated subgroup & $31.6(12.3 \mathrm{M} / 38.9 \mathrm{M})$ \\
\hline Statin-treated + LDL-C $<100 \mathrm{mg} / \mathrm{dl}$ subgroup & $27.6(6.0 \mathrm{M} / 21.7 \mathrm{M})$ \\
\hline Statin-treated + DM subgroup & $39.5(4.9 \mathrm{M} / 12.4 \mathrm{M})$ \\
\hline Statin-treated + ASCVD subgroup & $30.5(3.1 \mathrm{M} / 10.1 \mathrm{M})$ \\
\hline Statin-treated + DM or ASCVD subgroup & $34.4(6.4 \mathrm{M} / 18.6 \mathrm{M})$ \\
\hline
\end{tabular}

ASCVD: Atherosclerotic cardiovascular disease; DM: Diabetes mellitus; LDL-C: Low-density lipoprotein cholesterol; M: Million; TG: Triglycerides.

Reproduced from [96] CC BY-NC 4.0

\section{Newly expanded FDA indication for IPE}

IPE is now approved in the US as an adjunct to maximally tolerated statin therapy to reduce the risk of MI, stroke, coronary revascularization and unstable angina requiring hospitalization in adult patients with elevated TG levels $(\geq 150 \mathrm{mg} / \mathrm{dl})$ and established CVD or diabetes mellitus and two or more additional risk factors for CVD [8].

\section{Maximally tolerated statin therapy}

Maximally tolerated statin therapy is defined as the highest intensity and frequency of a statin that can be tolerated, which, in the case of statin-intolerant patients, would be no statin [87]. Statin intolerance is generally defined as unacceptable adverse effects or significant biomarker abnormalities that resolve with discontinuation of therapy and recur with re-challenge of at least two different statins (preferably statins using different metabolic pathways), with one of which prescribed at the lowest approved dose [87-89].

\section{Lipid parameters}

The expanded FDA indication for IPE does not specify any particular criteria for LDL-C; therefore, the choice of IPE should not be influenced by a patient's achieved LDL-C. In REDUCE-IT, patients treated with IPE had a cardiovascular benefit regardless of baseline LDL-C levels [9]. The expanded indication specifies that patients should have elevated TG levels $(\geq 150 \mathrm{mg} / \mathrm{dl})$, but, unlike the study criteria, does not specify any upper limit for TG levels and does not require that the TG levels be obtained in the fasting state. REDUCE-IT included a number of patients with TG levels $>500 \mathrm{mg} / \mathrm{dl}$; significant CVD event reduction was demonstrated by IPE versus placebo in all TG subgroups [73]. Again, IPE demonstrated benefits on CVD event risk reduction, irrespective of baseline or on-treatment TG levels.

\section{At-risk population}

In addition to being on maximally tolerated statin therapy and having TG levels $\geq 150 \mathrm{mg} / \mathrm{dl}$, the at-risk population eligible for IPE, as defined in the expanded indication, should have either established CVD or diabetes mellitus with $\geq 2$ additional risk factors for CVD. In REDUCE-IT, established CVD was described as a prior cardiovascular event, such as ischemic stroke, MI, or cardiovascular revascularization, as well as coronary artery disease, peripheral artery disease, carotid artery disease and/or cerebrovascular disease $[8,90]$. Of note, the expanded indication for IPE does not specify a minimum or maximum age for adults. Diabetes mellitus encompasses both Type 1 and Type 2 diabetes. Finally, additional CVD risk factors or risk enhancers may include hypertension; smoking history; family history of CVD [91]; older age ( $\geq 55$ years in men; $\geq 65$ years in women); hypercholesterolemia [92]; low HDL-C levels ( $\leq 40$ in men; $\leq 50$ in women); hsCRP level $>3.0 \mathrm{mg} / \mathrm{l}$; body mass index $>25 \mathrm{~kg} / \mathrm{m}^{2}$ [93]; microalbuminuria; renal dysfunction; chronic kidney disease; end-stage renal disease [94]; peripheral vascular disease; and physical inactivity $[8,90,95]$.

The size of the at-risk population can be estimated with available data. Based on an analysis of NHANES data from 2007 to 2014, a projected 38.9 million patients in the US are on statin therapy; $31.6 \%$ (12.3 million) of these statin-treated patients have TG levels $\geq 150 \mathrm{mg} / \mathrm{dl}$, and $34.4 \%$ have established ASCVD or diabetes (Table 5) [96]. Of interest, approximately 6-12 million adult patients with a clinical indication for statin therapy may be statinintolerant and, among these patients, those with TG levels $\geq 150 \mathrm{mg} / \mathrm{dl}$ could potentially benefit from treatment with IPE [97,98]. 


\section{Cost-effectiveness of IPE}

A report by the Institute for Clinical and Economic Review found that, based on findings from REDUCE-IT, IPE versus optimal medical management results in a cost of $\$ 18,000$ per quality-adjusted life-year (QALY) gained (well below the historical cost-effectiveness threshold of $\$ 50,000$ per QALY gained) [99]. Thus, IPE was considered 'high long-term value for money' [99]. This cost/QALY decreased to $\$ 16,000$ when revascularization and unstable angina were included in the base model. From a health economics perspective IPE represents an optimal therapeutic, a low-cost, effective treatment for a highly prevalent disorder.

Preliminary findings from a cost-effectiveness analysis that combined patient-level in-trial cost and clinical outcomes and long-term costs, events and life expectancy derived from Markov simulation models were presented at the 2019 AHA meeting [100]. Using treatment effects from REDUCE-IT, national healthcare costs and estimated net costs for IPE of $\$ 4.16 /$ day, the QALYs for IPE and control were 3.34 and 3.27, respectively. Mean costs in the trial were $\$ 27,576$ and $\$ 28,205$, respectively, demonstrating improved healthcare outcomes at lower healthcare costs. IPE was found to be cost saving in $70 \%$ of simulations. In addition, IPE was not only cost-effective in the treatment of patients at high risk for CVD, but also was projected to reduce long-term healthcare costs over patients' lifetimes [100]. A subsequent patient-level cost-effectiveness analysis that focused on US participants from REDUCE-IT found that the probability of IPE being cost-effective at thresholds of $\$ 50,000, \$ 100,000$ and $\$ 150,000$ per QALY gained was demonstrated in $>99 \%$ of simulations [101]. In primary prevention, the incremental cost-effectiveness ratio was $\$ 36,118$ per QALY gained, and the probability of IPE being cost-effective was shown in $62.3,79.1$ and $83.5 \%$ of simulations at thresholds of $\$ 50,000, \$ 100,000$ and $\$ 150,000$ per QALY gained, respectively. In secondary prevention, IPE was dominant in $98.6 \%$ of simulations, with the probability of being cost-effective shown in $100 \%$ of simulations for each of the per-QALY-gained thresholds.

Thus, these cost-effectiveness analysis findings for IPE, along with the clinical efficacy and safety data from REDUCE-IT, suggest that IPE is an inexpensive, safe and effective therapy that lowers CVD risk for a large high-risk population.

\section{Discussion \& conclusion}

Hypertriglyceridemia is associated with increased ASCVD risk, independent of LDL-C control [6]. Statin-treated patients may have persistent cardiovascular risk despite achieving optimal levels of LDL-C with statins, with or without other LDL-C-lowering treatments; in fact, among statin-treated patients, up to $70 \%$ of residual risk persists in multiple placebo-controlled studies [102-106]. However, outcomes trials in which residual risk was targeted by addition of TG-lowering treatments such as fibrates and niacin to statins did not show ASCVD risk reduction [32,33,38]. Similarly, trials of mixed omega-3 fatty acids have generally failed to demonstrate ASCVD risk reduction among patients with varying levels of baseline statin use [56-61].

By contrast, REDUCE-IT demonstrated that addition of IPE to statin treatment in patients with high TG and controlled LDL-C reduced important first ASCVD events by $25 \%$ [9] and, among the US cohort of 3146 patients, reduced total ASCVD events by $30 \%$ [72]. Following the positive findings from REDUCE-IT, the FDA approved an expanded indication for IPE as an adjunct to maximally tolerated statin therapy to reduce the risk of MI, stroke, coronary revascularization and unstable angina requiring hospitalization in adults with elevated TG levels $(\geq 150 \mathrm{mg} / \mathrm{dl}$ ) and established CVD or diabetes mellitus and two or more additional risk factors for CVD [8]. This new indication enables use of IPE to reduce the risk of ASCVD events for a large at-risk population. Results of recent cost analyses incorporating REDUCE-IT findings support that IPE is a cost-effective option for ASCVD residual risk reduction $[99,100]$.

Other large CV outcomes trials of TG-lowering treatments in statin-treated patients with hypertriglyceridemia have not yet shown encouraging results. The STRENGTH trial, designed to investigate whether addition of $4 \mathrm{~g} /$ day of an EPA + DHA mixture to statin treatment in high-risk adults with hypertriglyceridemia would reduce CVD events, was recently discontinued early as the EPA + DHA combination was unlikely to demonstrate a benefit to patients [67-69]. Detailed findings of the STRENGTH trial have not yet been published. The ongoing PROMINENT trial will clarify whether addition of pemafibrate to statin treatment in patients with type 2 diabetes and elevated TG can reduce CVD event risk [43].

IPE represents the first TG-lowering treatment option that effectively lowers residual CVD risk. Of note, IPE demonstrated significant ASCVD event reduction in REDUCE-IT, independent of TG levels. Thus, it is likely that multifactorial pleiotropic mechanisms of IPE, beyond TG lowering, contributed to ASCVD risk reduction. 
The expanded FDA indication will allow a larger at-risk population access to this cost-effective treatment for CVD event prevention.

\section{Future perspective}

The REDUCE-IT results demonstrate an important adjunctive approach to reducing residual CV risk beyond LDL-C reduction with a statin. IPE reduced all major CV end points, including CV mortality over and above those observed with a statin in patients with well-controlled LDL-C levels [9]. These benefits were observed independent of baseline or attained TG levels [73]. This suggests that the benefits observed with IPE were largely attributed to changes in EPA levels, as opposed to changes in lipid biomarker levels [74]. Much more work will have to be performed to more fully ascertain the mechanistic basis for these benefits, as it is likely that IPE acts through a variety of pleiotropic effects.

Atherosclerosis is a chronic inflammatory disease [107]. It is established that EPA is a parent molecule for downstream E series resolvins ( $\mathrm{RvE} 1, \mathrm{RvE} 2, \mathrm{RvE} 3)$, which are specialized molecules that resolve inflammation [108]. RvE1 has been found to attenuate LTB4-induced proinflammatory signaling and polymorphonuclear leukocyte migration, and RvE3 has shown potent inhibitory action on neutrophil chemotaxis [79,109]. RvE2 has demonstrated upregulating effects on macrophage phagocytosis and IL-10 production [80]. Consistent with this, EPA has been shown to: reduce circulating levels of pro-inflammatory eicosanoids (prostaglandins and leukotrienes) as well as IL$1 \beta$ and TNF- $\alpha$ [110-116]; reduce inflammation by inhibiting endothelial cell adhesion molecule expression (ICAM-1, VCAM-1) which reduces the binding and transmigration of monocytes and Thelper cells, thereby preventing their entry into the subendothelial space, an early event in atherogenesis [117-120]; inhibit the translocation of transcription regulator nuclear factor- $\kappa \mathrm{B}(\mathrm{NF}-\mathrm{\kappa} \mathrm{B})$ into the nucleus and the activation of inflammation pathways [75,121]; suppress the expression of pro-inflammatory cytokines by $\mathrm{T}$ helper cells and stimulate production of IL-10, a potent antiinflammatory cytokine [122,123]; and inhibit activation of the nucleotide-binding oligomerization domain, leucinerich-containing receptor family pyrin domain-containing 3 (NLRP3) inflammasome [124,125]. The remarkable findings of a $48 \%$ relative risk reduction in cardiac arrest and a $31 \%$ relative risk reduction in sudden cardiac death in the REDUCE-IT treatment group suggest that EPA may exert anti-arrhythmogenic influences on the ventricles, an issue that warrants intensive further investigation [9].

It is anticipated that the clinical benefits of IPE will likely extend into other areas of medicine. EPA has bacteriostatic and bactericidal properties in vitro and is being studied as an anti-infective agent [126-129]. Because of its anti-inflammatory effects, EPA is being evaluated as a potential means by which to resolve tissue damage following normal inflammatory responses to infection $[124,130]$. EPA may also play a role in inhibiting the development of cytokine storm syndrome in patients who are septic or infected with influenza or COVID-19 (severe acute respiratory syndrome coronavirus 2 [SARS-CoV-2]) based on evidence suggesting that unsaturated fatty acids inactivate enveloped viruses, enhancing recovery from these infections [131]. Pilot trials of EPA (NCT04335032, NCT04323228) and specifically IPE (NCT04412018) in patients with COVID-19 are in early stages. Due to its ability to control inflammation and modulate the composition of the gut microbiome, EPA is being used in clinical trials to ascertain its impact on inflammatory bowel diseases and risk for colon polyps and cancer [124,132,133]. EPA's potential role in reducing the risk of cognitive defects such as Alzheimer's disease and vascular dementia [134,135] and depression $[136,137]$ has also been previously studied. Given its tolerability and low potential for toxicity, the potential therapeutic efficacy of IPE across such a broad clinical spectrum of disease has aroused considerable interest. The results of randomized clinical trials are eagerly awaited.

\section{Executive summary}

\section{Hypertriglyceridemia}

- Hypertriglyceridemia is associated with increased cardiovascular disease (CVD) risk, independent of low-density lipoprotein cholesterol (LDL-C) control.

- Among adults in the USA aged $\geq 45$ years, the additional annual cost burden of having triglyceride (TG) levels $\geq 150 \mathrm{mg} / \mathrm{dl}$ compared with $<150 \mathrm{mg} / \mathrm{dl}$ is estimated to be over $\$ 10$ billion.

TG-lowering drugs \& cardiovascular outcomes

- Niacin, fibrates and mixed (eicosapentaenoic acid [EPA] + docosahexaenoic acid [DHA]) omega-3 fatty acids have TG-lowering effects; however, large outcomes trials evaluating these treatments as add-on therapy to statins have failed to demonstrate reductions in CVD events. 
- An open-label clinical trial of the omega-3 fatty acid EPA alone demonstrated that in Japanese patients, moderate-dose EPA ( $1.8 \mathrm{~g}$ daily) in addition to low-dose statin treatment significantly reduced ASCVD events by $19 \%$ compared with the statin-only control $(p=0.011)$.

\section{Overview of REDUCE-IT}

- The randomized, controlled Reduction of Cardiovascular Events with Icosapent Ethyl-Intervention Trial (REDUCE-IT) found that in statin-treated patients with elevated TG levels and high risk for CVD, addition of icosapent ethyl (IPE), a highly purified, stable ethyl ester of EPA (4 g/day), significantly reduced the occurrence of CVD events (cardiovascular death, nonfatal myocardial infarction [MI], nonfatal stroke, coronary revascularization, or unstable angina) by $25 \%$ compared with control (statin plus placebo) $(p<0.0001)$.

- The significant reduction in both the primary and key secondary CVD efficacy end points by IPE as add-on therapy to statin compared with placebo in REDUCE-IT was independent of both baseline and achieved TG levels, suggesting that additional pleiotropic mechanisms of EPA contributed to the CVD risk reduction.

IPE's expanded US FDA indication

- Based on REDUCE-IT findings, IPE now has an expanded indication in the US as an adjunct to maximally tolerated statin therapy to reduce the risk of $\mathrm{MI}$, stroke, coronary revascularization and unstable angina requiring hospitalization in adult patients with elevated TG levels $(\geq 150 \mathrm{mg} / \mathrm{dl})$ and either established CVD or diabetes mellitus plus two or more additional risk factors for CVD.

- Important points of clarification related to this expanded indication include that maximally tolerated statin therapy is considered the highest tolerated intensity and frequency of a statin, which for statin-intolerant patients would be no statin. There is no requirement for any particular target LDL-C level being attained prior to consideration of IPE therapy for patients with TG levels $\geq 150 \mathrm{mg} / \mathrm{dl}$ (either fasting or non-fasting) and a high risk for CVD events.

At-risk population

- Approximately 12 million statin-treated patients in the US have TG levels $\geq 150 \mathrm{mg} / \mathrm{dl}$, of whom approximately $50 \%$ have established ASCVD or diabetes.

- An estimated $\sim 4$ million adults may be statin intolerant and, among these patients, those with TG levels $\geq 150 \mathrm{mg} / \mathrm{dl}$ and high CVD risk could potentially benefit from treatment with IPE.

Cost-effectiveness of IPE

- An analysis by the Institute for Clinical and Economic Review based on REDUCE-IT data found IPE resulted in a cost of $\$ 18,000$ per quality-adjusted life-year (QALY) gained versus optimal medical management - well below the most conservative cost-effectiveness threshold of $\$ 50,000 / \mathrm{QALY}$ gained.

- Patient-level cost-effectiveness analyses based on REDUCE-IT data report that IPE improves healthcare outcomes at lower healthcare costs than placebo, and, among US participants, is cost-effective at $\$ 50,000, \$ 100,000$, and $\$ 150,000$ per-QALY-gained thresholds.

Financial \& competing interests disclosure

WE Boden: Grant/Research Support: Amgen, Janssen, BMS; Speaker's Bureau: Amarin, Servier. S Baum: Speaker's Bureaus: Akcea, Amgen, Boehringer Ingelheim, Eli Lilly, Novo Nordisk; Consultant: Akcea, Amgen, Regeneron, Sanofi, Novo Nordisk, Guidepoint Global, GLG Group; Advisory Boards: Akcea, Amgen, Esperion, Regeneron, Sanofi. PP Toth: Speaker's Bureaus: Amarin, Amgen, Esperion, Novo Nordisk; Consultant: Amarin, Amgen, Novartis, Kowa. S Fazio: Consultant: Amarin, Amgen, Esperion, Novartis, Novo Nordisk, Kowa. DL Bhatt: Dr. Bhatt serves as the Chair and International Principal Investigator for REDUCE-IT, with research funding from Amarin to Brigham and Women's Hospital. Dr. Bhatt discloses the following relationships - Advisory Board: Cardax, CellProthera, Cereno Scientific, Elsevier Practice Update Cardiology, Level Ex, Medscape Cardiology, PhaseBio, PLx Pharma, Regado Biosciences; Board of Directors: Boston VA Research Institute, Society of Cardiovascular Patient Care, TobeSoft; Chair: American Heart Association Quality Oversight Committee; Data Monitoring Committees: Baim Institute for Clinical Research (formerly Harvard Clinical Research Institute, for the PORTICO trial, funded by St. Jude Medical, now Abbott), Cleveland Clinic (including for the ExCEED trial, funded by Edwards), Contego Medical (Chair, PERFORMANCE 2), Duke Clinical Research Institute, Mayo Clinic, Mount Sinai School of Medicine (for the ENVISAGE trial, funded by Daiichi Sankyo), Population Health Research Institute; Honoraria: American College of Cardiology (Senior Associate Editor, Clinical Trials and News, ACC.org; Vice Chair, ACC Accreditation Committee), Baim Institute for Clinical Research (formerly Harvard Clinical Research Institute; RE-DUAL PCI clinical trial steering committee funded by Boehringer Ingelheim; AEGIS-II executive committee funded by CSL Behring), Belvoir Publications (Editor in Chief, Harvard Heart Letter), Duke Clinical Research Institute (clinical trial steering committees, including for the PRONOUNCE trial, funded by Ferring Pharmaceuticals), HMP Global (Editor in Chief, Journal of Invasive Cardiology), Journal of the American College of Cardiology (Guest Editor; Associate Editor), K2P (Co-Chair, interdisciplinary curriculum), Level Ex, Medtelligence/ReachMD (CME steering committees), MJH Life Sciences, Population Health Research Institute (for the COMPASS operations committee, publications committee, steering committee, and USA national co-leader, funded by Bayer), Slack Publications (Chief Medical Editor, Cardiology Today's Intervention), Society of Cardiovascular Patient Care (Secretary/Treasurer), WebMD (CME steering com- 
mittees); Other: Clinical Cardiology (Deputy Editor), NCDR-ACTION Registry Steering Committee (Chair), VA CART Research and Publications Committee (Chair); Research Funding: Abbott, Afimmune, Amarin, Amgen, AstraZeneca, Bayer, Boehringer Ingelheim, Bristol-Myers Squibb, Cardax, Chiesi, CSL Behring, Eisai, Ethicon, Ferring Pharmaceuticals, Forest Laboratories, Fractyl, Idorsia, Ironwood, Ischemix, Lexicon, Lilly, Medtronic, Pfizer, PhaseBio, PLx Pharma, Regeneron, Roche, Sanofi Aventis, Synaptic, The Medicines Company; Royalties: Elsevier (Editor, Cardiovascular Intervention: A Companion to Braunwald's Heart Disease); Site Co-Investigator: Biotronik, Boston Scientific, CSI, St. Jude Medical (now Abbott), Svelte; Trustee: American College of Cardiology; Unfunded Research: FlowCo, Merck, Novo Nordisk, Takeda. The authors have no other relevant affiliations or financial involvement with any organization or entity with a financial interest in or financial conflict with the subject matter or materials discussed in the manuscript apart from those disclosed.

Medical writing support was provided by Peloton Advantage, LLC, an OPEN Health company, Parsippany, NJ, USA, and was funded by Amarin Pharma, Inc., Bridgewater, NJ, USA.

\section{Open access}

This work is licensed under the Attribution-NonCommercial-NoDerivatives 4.0 Unported License. To view a copy of this license, visit http://creativecommons.org/licenses/by-nc-nd/4.0/

\section{References}

Papers of special note have been highlighted as: $\bullet$ of interest; $\bullet \bullet$ of considerable interest

1. Benjamin EJ, Muntner P, Alonso A et al. Heart disease and stroke statistics-2019 update: a report from the American Heart Association. Circulation 139(10), e56-e528 (2019).

2. World Health Organization. The top 10 causes of death. Geneva, Switzerland, 2018. https://www.who.int/news-room/fact-sheets/detail/the-top-10-causes-of-death.

3. Mokdad AH, Ballestros K, Echko M et al. The State of US Health, 1990-2016: Burden of diseases, injuries, and risk factors among US states. JAMA 319(14), 1444-1472 (2018).

4. Roth GA, Johnson C, Abajobir A et al. Global, regional, and national burden of cardiovascular diseases for 10 causes, 1990 to 2015 . J. Am. Coll. Cardiol. 70(1), 1-25 (2017)

5. Heron M. Deaths: Leading causes for 2017. Natl Vital Stat. Rep. 68(6), 1-77 (2019).

6. Toth PP, Granowitz C, Hull M, Liassou D, Anderson A, Philip S. High triglycerides are associated with increased cardiovascular events, medical costs, and resource utilization: a real-world administrative claims analysis of statin-treated patients with high residual cardiovascular risk. J. Am. Heart Assoc. 7(15), e008740 (2018).

7. Ganda OP, Bhatt DL, Mason RP, Miller M, Boden WE. Unmet need for adjunctive dyslipidemia therapy in hypertriglyderidemia management. J. Am. Coll. Cardiol. 72(3), 330-343 (2018).

8. Vascepa [package insert] Amarin Pharma Inc., Bridgewater, NJ (2019).

9. Bhatt DL, Steg G, Miller M et al. Cardiovascular risk reduction with icosapent ethyl for hypertriglyceridemia. N. Engl. J. Med. 380(1), 11-22 (2019).

-• REDUCE-IT showed that use of $4 \mathrm{~g}$ of icosapent ethyl was superior to placebo in reducing important atherosclerotic cardiovascular disease (ASCVD) events among patients with relatively controlled low-density lipoprotein cholesterol levels, elevated triglyceride levels, and either known ASCVD or those at high risk for developing ASCVD.

10. Miller M, Stone NJ, Ballantyne C et al. Triglycerides and cardiovascular disease: a scientific statement from the American Heart Association. Circulation 123(20), 2292-2333 (2011).

11. Quispe R, Hendrani AD, Baradaran-Noveiry B et al. Characterization of lipoprotein profiles in patients with hypertriglyceridemic Fredrickson-Levy and Lees dyslipidemia phenotypes: the Very Large Database of Lipids Studies 6 and 7. Arch. Med. Sci. 15(5), 1195-1202 (2019).

12. Rygiel K. Hypertriglyceridemia - common causes, prevention and treatment strategies. Curr. Cardiol. Rev. 14(1), 67-76 (2018).

13. Dron JS, Hegele RA. Genetics of triglycerides and the risk of atherosclerosis. Curr. Atheroscler. Rep. 19(7), 31 (2017).

14. Sundaram M, Curtis KR, Amir Alipour M et al. The apolipoprotein C-III (Gln38Lys) variant associated with human hypertriglyceridemia is a gain-of-function mutation. J. Lipid Res. 58(11), 2188-2196 (2017).

15. Stitziel N, Stirrups K, Masca N et al. Coding variation in ANGPTL4, LPL, and SVEP1 and the risk of coronary disease. N. Engl. J. Med. 374(12), 1134-1144 (2016).

16. Johansen CT, Wang J, Lanktree MB et al. Excess of rare variants in genes identified by genome-wide association study of hypertriglyceridemia. Nat. Genet. 42(8), 684-687 (2010).

17. Chatterjee C, Sparks DL. Hepatic lipase, high density lipoproteins, and hypertriglyceridemia. Am. J. Pathol. 178(4), 1429-1433 (2011). 
18. Fan W, Philip S, Granowitz C, Toth P, Wong N. Hypertriglyceridemia in statin-treated US adults: The National Health and Nutrition Examination Survey. J. Clin. Lipidol 13, 100-108 (2019).

- $\quad 25 \%$ of US adults, including a third of whom are on statin therapy for low-density lipoprotein cholesterol control, have elevated triglyceride levels. Over 3 million atherosclerotic cardiovascular disease events are expected to occur in this population, including 1 million events in patients on statin therapy, illustrating residual cardiovascular risk.

19. Palmer MK, Toth PP. Trends in lipids, obesity, metabolic syndrome, and diabetes mellitus in the United States: an NHANES analysis (2003-2004 to 2013-2014). Obesity (Silver Spring, Md.) 27(2), 309-314 (2019).

20. Nordestgaard BG. Triglyceride-rich lipoproteins and atherosclerotic cardiovascular disease: new insights from epidemiology, genetics, and biology. Circ. Res. 118(4), 547-563 (2016).

21. Kushner PA, Cobble ME. Hypertriglyceridemia: the importance of identifying patients at risk. Postgrad. Med. 128(8), 848-858 (2016).

22. Case BC, Bress AP, Kolm P et al. The economic burden of hypertriglyceridemia among US adults with diabetes or atherosclerotic cardiovascular disease on statin therapy. J. Clin. Lipidol. 13(5), 754-761 (2019).

23. Bansal S, Buring JE, Rifai N, Mora S, Sacks FM, Ridker PM. Fasting compared with nonfasting triglycerides and risk of cardiovascular events in women. JAMA 298(3), 309-316 (2007).

24. Nordestgaard BG, Benn M, Schnohr P, Tybjaerg-Hansen A. Nonfasting triglycerides and risk of myocardial infarction, ischemic heart disease, and death in men and women. JAMA 298(3), 299-308 (2007).

25. Toth PP, Philip S, Hull M, Granowitz C. Association of elevated triglycerides with increased cardiovascular risk and direct costs in statin-treated patients. Mayo Clin Proc. 94(9), 1670-1680 (2019).

26. Toth PP, Fazio S, Wong ND, Hull M, Nichols GA. Risk of cardiovascular events in patients with hypertriglyceridemia: a review of real-world evidence. Diabetes Obes. Metab. 22(3), 279-289 (2020).

27. Nichols GA, Philip S, Reynolds K, Granowitz CB, Fazio S. Increased cardiovascular risk in hypertriglyceridemic patients with statin-controlled LDL cholesterol. J. Clin. Endocrinol. Metab. 103(8), 3019-3027 (2018).

28. Liu J, Zeng FF, Liu ZM, Zhang CX, Ling WH, Chen YM. Effects of blood triglycerides on cardiovascular and all-cause mortality: a systematic review and meta-analysis of 61 prospective studies. Lipids Health Dis. 12, 159 (2013).

29. Jorgensen AB, Frikke-Schmidt R, West AS, Grande P, Nordestgaard BG, Tybjaerg-Hansen A. Genetically elevated non-fasting triglycerides and calculated remnant cholesterol as causal risk factors for myocardial infarction. Eur. Heart J. 34(24), 1826-1833 (2013)

30. Varbo A, Benn M, Tybjaerg-Hansen A, Jorgensen AB, Frikke-Schmidt R, Nordestgaard BG. Remnant cholesterol as a causal risk factor for ischemic heart disease. J. Am. Coll. Cardiol. 61(4), 427-436 (2013).

31. Budoff M. Triglycerides and triglyceride-rich lipoproteins in the causal pathway of cardiovascular disease. Am. J. Cardiol. 118(1), 138-145 (2016).

32. The AIM-HIGH Investigators et al.The AIM-HIGH Investigators, Boden WE, Probstfield JL et al. Niacin in patients with low HDL cholesterol levels receiving intensive statin therapy. N. Engl. J. Med. 365(24), 2255-2267 (2011).

33. The HPS2-THRIVE Collaborative Group. Effects of extended-release niacin with laropiprant in high-risk patients. N. Engl. J. Med. 371(3), 203-212 (2014).

34. Guyton JR, Slee AE, Anderson T et al. Relationship of lipoproteins to cardiovascular events: the AIM-HIGH trial (Atherothrombosis Intervention in Metabolic Syndrome With Low HDL/High Triglycerides and Impact on Global Health Outcomes). J. Am. Coll. Cardiol. 62(17), 1580-1584 (2013).

35. Rubins HB, Robins SJ, Collins D et al. Gemfibrozil for the secondary prevention of coronary heart disease in men with low levels of high-density lipoprotein cholesterol: Veterans Affairs High-Density Lipoprotein Cholesterol Intervention Trial Study Group. N. Engl. J. Med. 341(6), 410-418 (1999).

36. The FIELD Study Investigators et al.The FIELD Study Investigators, Keech A, Simes RJ et al. Effects of long-term fenofibrate therapy on cardiovascular events in 9795 people with type 2 diabetes mellitus (the FIELD study): randomised controlled trial. Lancet 366(9500), 1849-1861 (2005).

37. BIP Study Group. Secondary prevention by raising HDL cholesterol and reducing triglycerides in patients with coronary artery disease. Circulation 102(1), 21-27 (2000).

38. The ACCORD Study Group et al.The ACCORD Study Group, Ginsberg HN, Elam MB et al. Effects of combination lipid therapy in type 2 diabetes mellitus. N. Engl. J. Med. 362(17), 1563-1574 (2010).

39. Jacobson TA, Zimmerman FH. Fibrates in combination with statins in the management of dyslipidemia. J. Clin. Hypertens. (Greenwich) 8(1), 35-41; quiz 42-33 (2006).

40. Wiggins BS, Saseen JJ et al., Page RL 2nd Recommendations for management of clinically significant drug-drug interactions with statins and select agents used in patients with cardiovascular disease: a scientific statement from the American Heart Association. Circulation 134(21), e468-e495 (2016).

41. Cardiovascular disease and risk management: standards of medical care in diabetes-2020. Diabetes Care 43(Suppl. 1), S111-s134 (2020). 
42. Gustavson LE, Schweitzer SM, Burt DA et al. Evaluation of the potential for pharmacokinetic interaction between fenofibrate and ezetimibe: A phase I, open-label, multiple-dose, three-period crossover study in healthy subjects. Clin. Ther. 28(3), 373-387 (2006).

43. Pradhan AD, Paynter NP, Everett BM et al. Rationale and design of the Pemafibrate to Reduce Cardiovascular Outcomes by Reducing Triglycerides in Patients with Diabetes (PROMINENT) study. Am. Heart J. 206, 80-93 (2018).

44. Skulas-Ray AC, Wilson PWF, Harris WS et al. Omega-3 fatty acids for the management of hypertriglyceridemia: a science advisory from the American Heart Association. Circulation 140(12), e673-e691 (2019).

45. Jacobson TA, Glickstein SB, Rowe JD, Soni PN. Effects of eicosapentaenoic acid and docosahexaenoic acid on low-density lipoprotein cholesterol and other lipids: a review. J. Clin. Lipidol. 6(1), 5-18 (2012).

46. Nelson JR, True WS, Le V, Mason RP. Can pleiotropic effects of eicosapentaenoic acid (EPA) impact residual cardiovascular risk? Postgrad. Med. 129(8), 822-827 (2017).

47. Borow KM, Nelson JR, Mason RP. Biologic plausibility, cellular effects, and molecular mechanisms of eicosapentaenoic acid (EPA) in atherosclerosis. Atherosclerosis 242(1), 357-366 (2015).

48. Wang H, Chen J, Zhao L. N-3 polyunsaturated fatty acids for prevention of postoperative atrial fibrillation: updated meta-analysis and systematic review. J. Interv. Card. Electrophysiol. 51(2), 105-115 (2018).

49. Ramadeen A, Connelly KA, Leong-Poi H et al. Docosahexaenoic acid, but not eicosapentaenoic acid, supplementation reduces vulnerability to atrial fibrillation. Circ. Arrhythm. Electrophysiol. 5(5), 978-983 (2012).

50. Mason RP. New insights into mechanisms of action for omega-3 fatty acids in atherothrombotic cardiovascular disease. Curr. Atheroscler. Rep. 21(2), (2019).

51. Mason RP, Libby P, Bhatt DL. Emerging mechanisms of cardiovascular protection for the omega-3 fatty acid eicosapentaenoic acid. Arterioscler. Thromb. Vasc. Biol. 40(5), 1135-1147 (2020).

52. Deckelbaum RJ, Calder PC. Editorial: Is it time to separate EPA from DHA when using omega-3 fatty acids to protect heart and brain? Curr. Opin. Clin. Nutr. Metab. Care 23(2), 65-67 (2020).

53. Dyall SC. Long-chain omega-3 fatty acids and the brain: a review of the independent and shared effects of EPA, DPA and DHA. Front. Aging Neurosci. 7, 52 (2015).

54. Zhao Z, Wen $\mathrm{H}$, Fefelova $\mathrm{N}$ et al. Docosahexaenoic acid reduces the incidence of early afterdepolarizations caused by oxidative stress in rabbit ventricular myocytes. Front. Physiol. 3, 252 (2012).

55. GISSI Prevenzione Investigators. Dietary supplementation with n-3 polyunsaturated fatty acids and vitamin $\mathrm{E}$ after myocardial infarction: results of the GISSI-Prevenzione trial. Gruppo Italiano per lo Studio della Sopravvivenza nell'Infarto miocardico. Lancet 354(9177), 447-455 (1999).

56. Rauch B, Schiele R, Schneider S et al. OMEGA, a randomized, placebo-controlled trial to test the effect of highly purified omega-3 fatty acids on top of modern guideline-adjusted therapy after myocardial infarction. Circulation 122(21), 2152-2159 (2010).

57. ORIGIN Trial Investigators. n-3 Fatty acids and cardiovascular outcomes in patients with dysglycemia. N. Engl. J. Med. 367(4), 309-318 (2012).

58. Kromhout D, Giltay EJ, Geleijnse JM. n-3 Fatty acids and cardiovascular events after myocardial infarction. N. Engl. J. Med. 363(21), 2015-2026 (2010).

59. The Risk and Prevention Study Collaborative Group. n-3 Fatty acids in patients with multiple cardiovascular risk factors: the Risk and Prevention Study Collaborative Group. N. Engl. J. Med. 368, 1800-1808 (2013).

60. ASCEND Study Collaborative Group et al.ASCEND Study Collaborative Group, Bowman L, Mafham M et al. Effects of n-3 fatty acid supplements in diabetes mellitus. N. Engl. J. Med. 379(16), 1540-1550 (2018).

61. Manson JE, Cook NR, Lee IM et al. Marine n-3 fatty acids and prevention of cardiovascular disease and cancer. N. Engl. J. Med. 380(1), 23-32 (2019).

62. GISSI-HF Investigators. Effect of $\mathrm{n}-3$ polyunsaturated fatty acids in patients with chronic heart failure (the GISSI-HF trial): a randomised, double-blind, placebo-controlled trial. Lancet 372(9645), 1223-1230 (2008).

63. Neumann FJ, Sousa-Uva M, Ahlsson A et al. 2018 ESC/EACTS Guidelines on myocardial revascularization. Eur. Heart J. 40(2), 87-165 (2019).

64. Rubenfire M. 2019 ACC/AHA guideline on the primary prevention of cardiovascular disease. American College of Cardiology, 2019. https://www.acc.org/latest-in-cardiology/ten-points-to-remember/2019/03/07/16/00/2019-acc-aha-guideline-on-primary-preventiongl-prevention.

65. Rizos EC, Ntzani EE, Bika E, Kostapanos MS, Elisaf MS. Association between omega-3 fatty acid supplementation and risk of major cardiovascular disease events: a systematic review and meta-analysis. JAMA 308(10), 1024-1033 (2012).

66. Siscovick DS, Barringer TA, Fretts AM et al. Omega-3 polyunsaturated fatty acid (fish oil) supplementation and the prevention of clinical cardiovascular disease: a science advisory from the American Heart Association. Circulation 135(15), e867-e884 (2017). 
67. Nicholls SJ, Lincoff AM, Bash D et al. Assessment of omega-3 carboxylic acids in statin treated patients with high levels of triglycerides and low levels of high density lipoprotein cholesterol: Rationale and design of the STRENGTH trial. Clin. Cardiol. 41(10), 1281-1288 (2018).

68. Slachta A. AstraZeneca stops Epanova trial early due to disappointing results. Cardiovascular Business, 2020. https://www.cardiovascularbusiness.com/node/159661/printable/print.

69. Update on Phase III STRENGTH trial for Epanova in mixed dyslipidaemia [press release]. AstraZeneca, 2020. https://www.astrazeneca. $\mathrm{com} /$ media-centre/press-releases/2020/update-on-phase-iii-strength-trial-for-epanova-in-mixed-dyslipidaemia-13012020.html.

70. Yokoyama M, Origasa $\mathrm{H}$, Matsuzaki $\mathrm{M}$ et al. Effects of eicosapentaenoic acid on major coronary events in hypercholesterolaemic patients (JELIS): a randomised open-label, blinded end point analysis. Lancet 369(9567), 1090-1098 (2007).

- A combination of a pure, low-dose eicosapentaenoic acid with a low-dose statin significantly reduced atherosclerotic cardiovascular disease events by $19 \%$ compared with placebo.

71. Bhatt DL, Steg PG, Miller M et al. Effects of icosapent ethyl on total ischemic events: from REDUCE-IT. J. Am. Coll. Cardiol. 73(22), 2791-2802 (2019).

-. Total (first and subsequent) primary end point atherosclerotic cardiovascular disease event rates in the icosapent ethyl group were reduced to 61 from 89 per 1000 patient-years, a $30 \%$ relative risk reduction, compared with placebo.

72. Bhatt DL, Miller M, Brinton EA et al. REDUCE-IT USA: results from the 3,146 patients randomized in the United States. Circulation 141(5), 367-375 (2020).

-• The USA subgroup analysis of REDUCE-IT demonstrated that icosapent ethyl provided a statistically significant $31 \%$ relative risk reduction in important atherosclerotic cardiovascular disease events compared with placebo.

73. Bhatt DL, Steg PG, Miller M et al. Reduction in first and total ischemic events with icosapent ethyl across baseline triglyceride tertiles. J. Am. Coll. Cardiol. 74(8), 1159-1161 (2019).

-• Icosapent ethyl reduced important atherosclerotic cardiovascular disease events in statin-treated patients across a wide range of baseline triglycerides, suggesting that the benefits of icosapent ethyl may be tied to nontriglyceride-related effects.

74. Bhatt DL, Miller M, Steg G et al. EPA levels and cardiovascular outcomes in the reduction of cardiovascular events with icosapent ethyl-intervention trial [oral presentation]. Presented at: Annual Scientific Session of the American College of Cardiology, Chicago, IL, 2020 (virtual). https://www.tctmd.com/slide/epa-levels-and-cardiovascular-outcomes-reduction-cardiovascular-events-icosapent-ethyl.

-• On-treatment eicosapentaenoic acid levels via icosapent ethyl correlated with the REDUCE-IT primary end point, key secondary end point, and most other cardiovascular end points. Benefits noted in REDUCE-IT were beyond those that could be explained by changes in biomarkers such as triglyceride, low-density lipoprotein cholesterol, high-density lipoprotein cholesterol, or high-sensitivity $\mathrm{C}$-reactive protein levels.

75. Cawood AL, Ding R, Napper FL et al. Eicosapentaenoic acid (EPA) from highly concentrated n-3 fatty acid ethyl esters is incorporated into advanced atherosclerotic plaques and higher plaque EPA is associated with decreased plaque inflammation and increased stability. Atherosclerosis 212(1), 252-259 (2010).

76. Nelson JR, Raskin S. The eicosapentaenoic acid:arachidonic acid ratio and its clinical utility in cardiovascular disease. Postgrad. Med. 131(4), 268-277 (2019).

77. Hasegawa T, Otsuka K, Iguchi T et al. Serum n-3 to n-6 polyunsaturated fatty acids ratio correlates with coronary plaque vulnerability: an optical coherence tomography study. Heart Vessels 29(5), 596-602 (2014).

78. Bays HE, Ballantyne CM, Braeckman RA, Stirtan WG, Soni PN. Icosapent ethyl, a pure ethyl ester of eicosapentaenoic acid: effects on circulating markers of inflammation from the MARINE and ANCHOR studies. Am. J. Cardiovasc. Drugs 13(1), 37-46 (2013).

79. Arita M, Ohira T, Sun YP, Elangovan S, Chiang N, Serhan CN. Resolvin E1 selectively interacts with leukotriene B4 receptor BLT1 and ChemR23 to regulate inflammation. J. Immunol. 178(6), 3912-3917 (2007).

80. Oh SF, Dona M, Fredman G, Krishnamoorthy S, Irimia D, Serhan CN. Resolvin E2 formation and impact in inflammation resolution. J. Immunol. 188(9), 4527-4534 (2012).

81. Budoff MJ. Effect of icosapent ethyl on progression of coronary atherosclerosis in patients with elevated triglycerides on statin therapy EVAPORATE. Presented at the American Heart Association Annual Scientific Sessions, Philadelphia, PA, November 18, 2019. https://www.acc.org/latest-in-cardiology/clinical-trials/2019/11/15/17/46/evaporate.

82. Food and Drug Administration. FDA Briefing Document: Endocrinologic and Metabolic Drugs Advisory Committee Meeting. 2019. https://www.fda.gov/advisory-committees/november-14-2019-meeting-endocrinologic-and-metabolic-drugs-advisory-committee-mee ting-announcement.

83. Lakshmanan S, Shekar C, Kinninger A et al. Comparison of mineral oil and non-mineral oil placebo on coronary plaque progression by coronary computed tomography angiography. Cardiovasc. Res. 116(3), 479-482 (2020).

84. Radel J, Pender D, Shah S. Effect of mineral oil on plasma lipida: a meta-analysis [abstract]. J. Am. Coll. Cardiol. $75(11$ Suppl. 1), 1908 (2020).

85. Amarin Corporation. Amarin announced FDA Advisory Committee voted unanimously (16-0) to recommend approval of Vascepa ${ }^{\circledR}$ (icosapent ethyl) capsules label expansion to reduce cardiovascular risk based on landmark REDUCE-IT ${ }^{\circledR}$ outcomes trial [press release]. 
https:

//investor.amarincorp.com/news-releases/news-release-details/amarin-announced-fda-advisory-committee-voted-unanimously-16-0.

86. Food and Drug Administration. FDA approves use of drug to reduce risk of cardiovascular events in certain adult patient groups [news release]. 2019. https://www.fda.gov/news-events/press-announcements/fda-approves-use-drug-reduce-risk-cardiovascular-events-certai n-adult-patient-groups.

87. Baum SJ, Toth PP, Underberg JA, Jellinger P, Ross J, Wilemon K. PCSK9 inhibitor access barriers-issues and recommendations: Improving the access process for patients, clinicians and payers. Clin. Cardiol. 40(4), 243-254 (2017).

88. Banach M, Rizzo M, Toth PP et al. Statin intolerance - an attempt at a unified definition. Position paper from an International Lipid Expert Panel. Arch. Med. Sci. 11(1), 1-23 (2015).

89. Lloyd-Jones DM, Morris PB, Ballantyne CM et al. 2016 ACC Expert Consensus Decision Pathway on the Role of Non-Statin Therapies for LDL-Cholesterol Lowering in the Management of Atherosclerotic Cardiovascular Disease Risk: A Report of the American College of Cardiology Task Force on Clinical Expert Consensus Documents. J. Am. Coll. Cardiol. 68(1), 92-125 (2016).

90. Bhatt DL, Steg PG, Brinton EA et al. Rationale and design of REDUCE-IT: reduction of cardiovascular events with icosapent ethyl-intervention trial. Clin. Cardiol. 40(3), 138-148 (2017).

91. Kolber MR, Scrimshaw C. Family history of cardiovascular disease. Can. Fam. Physician 60(11), 1016 (2014).

92. Lacoste L, Lam JY, Hung J, Letchacovski G, Solymoss CB, Waters D. Hyperlipidemia and coronary disease. Correction of the increased thrombogenic potential with cholesterol reduction. Circulation 92(11), 3172-3177 (1995).

93. Carbone S, Canada JM, Billingsley HE, Siddiqui MS, Elagizi A, Lavie CJ. Obesity paradox in cardiovascular disease: where do we stand? Vascular Health Risk Manage. 15, 89-100 (2019).

94. Cozzolino M, Mangano M, Stucchi A, Ciceri P, Conte F, Galassi A. Cardiovascular disease in dialysis patients. Nephrol. Dial. Transplant. 33(Suppl. 3), iii28-iii34 (2018).

95. National Lipid Association. NLA position on the use of icosapent ethyl in high and very-high risk patients. 2019. https://www.lipid.org/nla/nla-position-use-icosapent-ethyl-high-and-very-high-risk-patients.

96. Fan W, Philip S, Granowitz C, Toth PP, Wong ND. Prevalence of US adults with triglycerides $\geq 150 \mathrm{mg} / \mathrm{dl}$ : NHANES 2007-2014. Cardiol. Ther. 9(1), 207-213 (2020).

97. Toth PP, Patti AM, Giglio RV et al. Management of statin intolerance in 2018: still more questions than answers. Am. J. Cardiovasc. Drugs 18(3), 157-173 (2018).

98. Saeed B, Wright E, Evans M, Lewis M, Steinhubl S. Prevalence of statin intolerance in a high risk cohort and management strategies in contemporary cardiology [abstract PS1-45]. Clin. Med. Res. 11(3), 136 (2013).

99. Ollendorf D, McQueen R, Fazioli K et al. Additive therapies for cardiovascular disease: effectiveness and value. Institute for Clinical and Economic Review, 2019. http://icer-review.org/material/cvd-final-evidence-report/.

100. Weintraub WS, Bhatt DL, Zhang Z et al. Cost-effectiveness of icosapent ethyl in REDUCE-IT [abstract]. Presented at the American Heart Association Annual Scientific Sessions, Philadelphia, PA November 18, 2019.

101. Weintraub WS, Bhatt D, Zhang Z et al. Cost-effectiveness of icosapent ethyl in US REDUCE-IT patients [abstract]. J. Am. Coll. Cardiol. 75(11 Suppl. 1), 1914 (2020).

102. Kones R. Molecular sources of residual cardiovascular risk, clinical signals, and innovative solutions: relationship with subclinical disease, undertreatment, and poor adherence: implications of new evidence upon optimizing cardiovascular patient outcomes. Vascular Health Risk Manage. 9, 617-670 (2013).

103. Scandinavian Simvastatin Survival Study Investigators. Randomised trial of cholesterol lowering in 4444 patients with coronary heart disease: the Scandinavian Simvastatin Survival Study (4S). Lancet 344(8934), 1383-1389 (1994).

104. Sacks FM, Pfeffer MA, Moye LA et al. The effect of pravastatin on coronary events after myocardial infarction in patients with average cholesterol levels. N. Engl. J. Med. 335(14), 1001-1009 (1996).

105. Downs JR, Clearfield M, Weis S et al. Primary prevention of acute coronary events with lovastatin in men and women with average cholesterol levels: results of AFCAPS/TexCAPS. Air Force/Texas Coronary Atherosclerosis Prevention Study. JAMA 279(20), 1615-1622 (1998).

106. Colhoun HM, Betteridge DJ, Durrington PN et al. Primary prevention of cardiovascular disease with atorvastatin in type 2 diabetes in the Collaborative Atorvastatin Diabetes Study (CARDS): multicentre randomised placebo-controlled trial. Lancet 364(9435), 685-696 (2004).

107. Libby P, Nahrendorf M, Swirski FK. Leukocytes link local and systemic inflammation in ischemic cardiovascular disease: an expanded "Cardiovascular Continuum". J. Am. Coll. Cardiol. 67(9), 1091-1103 (2016).

108. Serhan CN, Chiang N, Van Dyke TE. Resolving inflammation: dual anti-inflammatory and pro-resolution lipid mediators. Nat. Rev. Immunol. 8(5), 349-361 (2008).

109. Isobe $\mathrm{Y}$, Arita M, Matsueda $\mathrm{S}$ et al. Identification and structure determination of novel anti-inflammatory mediator resolvin E3, 17,18-dihydroxyeicosapentaenoic acid. J. Biol. Chem. 287(13), 10525-10534 (2012). 
110. Hawthorne AB, Filipowicz BL, Edwards TJ, Hawkey CJ. High dose eicosapentaenoic acid ethyl ester: effects on lipids and neutrophil leukotriene production in normal volunteers. Br. J. Clin. Pharmacol. 30(2), 187-194 (1990).

111. Obata T, Nagakura T, Masaki T, Maekawa K, Yamashita K. Eicosapentaenoic acid inhibits prostaglandin D2 generation by inhibiting cyclo-oxygenase-2 in cultured human mast cells. Clin. Exp. Allergy 29(8), 1129-1135 (1999).

112. Terano T, Salmon JA, Higgs GA, Moncada S. Eicosapentaenoic acid as a modulator of inflammation. Effect on prostaglandin and leukotriene synthesis. Biochem. Pharmacol. 35(5), 779-785 (1986).

113. Prescott SM. The effect of eicosapentaenoic acid on leukotriene B production by human neutrophils. J. Biol. Chem. 259(12), 7615-7621 (1984).

114. Kondeti V, Al-Azzam N, Duah E, Thodeti CK, Boyce JA, Paruchuri S. Leukotriene D4 and prostaglandin E2 signals synergize and potentiate vascular inflammation in a mast cell-dependent manner through cysteinyl leukotriene receptor 1 and E-prostanoid receptor 3. J. Allergy Clin. Immunol. 137(1), 289-298 (2016).

115. Paschoal VA, Vinolo MA, Crisma AR, Magdalon J, Curi R. Eicosapentaenoic (EPA) and docosahexaenoic (DHA) acid differentially modulate rat neutrophil function in vitro. Lipids 48(2), 93-103 (2013).

116. Mickleborough TD, Tecklenburg SL, Montgomery GS, Lindley MR. Eicosapentaenoic acid is more effective than docosahexaenoic acid in inhibiting proinflammatory mediator production and transcription from LPS-induced human asthmatic alveolar macrophage cells. Clin. Nutr. 28(1), 71-77 (2009).

117. Huang CY, Sheu WH, Chiang AN. Docosahexaenoic acid and eicosapentaenoic acid suppress adhesion molecule expression in human aortic endothelial cells via differential mechanisms. Mol. Nutr. Food Res. 59(4), 751-762 (2015).

118. Chen CN, Chang SF, Lee PL et al. Neutrophils, lymphocytes, and monocytes exhibit diverse behaviors in transendothelial and subendothelial migrations under coculture with smooth muscle cells in disturbed flow. Blood 107(5), 1933-1942 (2006).

119. Watanabe T, Fan J. Atherosclerosis and inflammation mononuclear cell recruitment and adhesion molecules with reference to the implication of ICAM-1/LFA-1 pathway in atherogenesis. Int. J. Cardiol. 66(Suppl. 1), S45-53; discussion S55 (1998).

120. Matsumoto M, Sata M, Fukuda D et al. Orally administered eicosapentaenoic acid reduces and stabilizes atherosclerotic lesions in ApoE-deficient mice. Atherosclerosis 197(2), 524-533 (2008).

121. Zhao Y, Joshi-Barve S, Barve S, Chen LH. Eicosapentaenoic acid prevents LPS-induced TNF-alpha expression by preventing NF-kappaB activation. J. Am. Coll. Nutr. 23(1), 71-78 (2004).

122. Jaudszus A, Gruen M, Watzl B et al. Evaluation of suppressive and pro-resolving effects of EPA and DHA in human primary monocytes and T-helper cells. J. Lipid Res. 54(4), 923-935 (2013).

123. Kondo H, Abe I, Gotoh K et al. Interleukin 10 treatment ameliorates high-fat diet-induced inflammatory atrial remodeling and fibrillation. Circ. Arrhythm. Electrophysiol. 11(5), e006040 (2018).

124. Mo Z, Tang C, Li H et al. Eicosapentaenoic acid prevents inflammation induced by acute cerebral infarction through inhibition of NLRP3 inflammasome activation. Life Sci. 242, 117133 (2020).

125. Chen S, Wang Y, Pan Y et al. Novel role for tranilast in regulating NLRP3 ubiquitination, vascular inflammation, and atherosclerosis. J. Am. Heart Assoc. e015513 (2020).

126. Le PNT, Desbois AP. Antibacterial effect of eicosapentaenoic acid against Bacillus cereus and Staphylococcus aureus: killing kinetics, selection for resistance, and potential cellular target. Mar. Drugs 15(11), 334 (2017).

127. Shin SY, Bajpai VK, Kim HR, Kang SC. Antibacterial activity of bioconverted eicosapentaenoic (EPA) and docosahexaenoic acid (DHA) against foodborne pathogenic bacteria. Int. J. Food Microbiol. 113(2), 233-236 (2007).

128. Cheng CL, Huang SJ, Wu CL et al. Transgenic expression of omega-3 PUFA synthesis genes improves zebrafish survival during Vibrio vulnificus infection. J. Biomed. Sci. 22, 103 (2015).

129. Desbois AP, Lawlor KC. Antibacterial activity of long-chain polyunsaturated fatty acids against Propionibacterium acnes and Staphylococcus aureus. Mar. Drugs 11(11), 4544-4557 (2013).

130. D’Elia RV, Harrison K, Oyston PC, Lukaszewski RA, Clark GC. Targeting the “cytokine storm” for therapeutic benefit. Clin. Vaccine Immunol. 20(3), 319-327 (2013).

131. Das UN. Can bioactive lipids inactivate coronavirus (COVID-19)? Arch. Med. Res. (2020).

132. Piazzi G, D’Argenio G, Prossomariti A et al. Eicosapentaenoic acid free fatty acid prevents and suppresses colonic neoplasia in colitis-associated colorectal cancer acting on Notch signaling and gut microbiota. Int. J. Cancer 135(9), 2004-2013 (2014).

133. Scaioli E, Sartini A, Bellanova M et al. Eicosapentaenoic acid reduces fecal levels of calprotectin and prevents relapse in patients with ulcerative colitis. Clin. Gastroenterol. Hepatol. 16(8), 1268-1275.e1262 (2018).

134. de Souza Fernandes DP, Canaan Rezende FA, Pereira Rocha G, De Santis Filgueiras M, Silva Moreira PR, Gonçalves Alfenas Rde C. Effect of eicosapentaenoic acid and docosahexaenoic acid supplementations to control cognitive decline in dementia and Alzheimer's disease: a systematic review. Nutr. Hosp. 32(2), 528-533 (2015).

135. Samieri C, Féart C, Letenneur L et al. Low plasma eicosapentaenoic acid and depressive symptomatology are independent predictors of dementia risk. Am. J. Clin. Nutr. 88(3), 714-721 (2008). 
136. Bazinet RP, Metherel AH, Chen CT et al. Brain eicosapentaenoic acid metabolism as a lead for novel therapeutics in major depression. Brain. Behav. Immun. 85, 21-28 (2020).

137. Trebatická J, Hradečná Z, Surovcová A et al. Omega-3 fatty-acids modulate symptoms of depressive disorder, serum levels of omega-3 fatty acids and omega-6/omega-3 ratio in children. A randomized, double-blind and controlled trial. Psychiatry Res. 287, 112911 (2020). 